
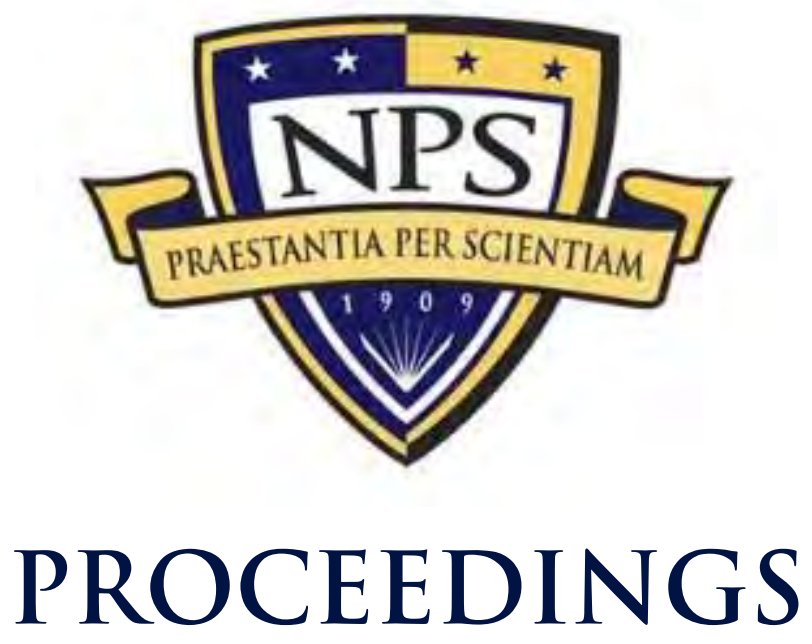

OF THE

ELEVENTH ANNUAL ACQUISITION RESEARCH SYMPOSIUM

\title{
THURSDAY SESSIONS VOLUME II
}

\section{The Cost Impacts of Jointness: Insights From the NPOESS Program}

Morgan Dwyer, Massachusetts Institute of Technology

Zoe Szajnfarber, George Washington University

Bruce Cameron, Massachusetts Institute of Technology Markus Bradford, Massachusetts Institute of Technology

Ed Crawley, Massachusetts Institute of Technology

Published April 30, 2014

Approved for public release; distribution is unlimited.

Prepared for the Naval Postgraduate School, Monterey, CA 93943. 


\section{Report Documentation Page}

Public reporting burden for the collection of information is estimated to average 1 hour per response, including the time for reviewing instructions, searching existing data sources, gathering and maintaining the data needed, and completing and reviewing the collection of information. Send comments regarding this burden estimate or any other aspect of this collection of information, including suggestions for reducing this burden, to Washington Headquarters Services, Directorate for Information Operations and Reports, 1215 Jefferson Davis Highway, Suite 1204, Arlington VA 22202-4302. Respondents should be aware that notwithstanding any other provision of law, no person shall be subject to a penalty for failing to comply with a collection of information if it does not display a currently valid OMB control number.

\begin{tabular}{|c|c|c|}
\hline $\begin{array}{l}\text { 1. REPORT DATE } \\
\mathbf{3 0} \text { APR } 2014\end{array}$ & 2. REPORT TYPE & $\begin{array}{l}\text { 3. DATES COVERED } \\
\mathbf{0 0 - 0 0 - 2 0 1 4} \text { to 00-00-2014 }\end{array}$ \\
\hline \multirow{3}{*}{\multicolumn{2}{|c|}{$\begin{array}{l}\text { 4. TITLE AND SUBTITLE } \\
\text { The Cost Impacts of Jointness: Insights From the NPOESS Program }\end{array}$}} & 5a. CONTRACT NUMBER \\
\hline & & 5b. GRANT NUMBER \\
\hline & & 5c. PROGRAM ELEMENT NUMBER \\
\hline \multirow{3}{*}{\multicolumn{2}{|c|}{ 6. AUTHOR(S) }} & 5d. PROJECT NUMBER \\
\hline & & 5e. TASK NUMBER \\
\hline & & 5f. WORK UNIT NUMBER \\
\hline \multicolumn{2}{|c|}{$\begin{array}{l}\text { 7. PERFORMING ORGANIZATION NAME(S) AND ADDRESS(ES) } \\
\text { Massachusetts Institute of Technology,Engineering Systems } \\
\text { Division,Cambridge,MA,02139 }\end{array}$} & $\begin{array}{l}\text { 8. PERFORMING ORGANIZATION } \\
\text { REPORT NUMBER }\end{array}$ \\
\hline \multirow{2}{*}{\multicolumn{2}{|c|}{ 9. SPONSORING/MONITORING AGENCY NAME(S) AND ADDRESS(ES) }} & 10. SPONSOR/MONITOR'S ACRONYM(S) \\
\hline & & $\begin{array}{l}\text { 11. SPONSOR/MONITOR'S REPORT } \\
\text { NUMBER(S) }\end{array}$ \\
\hline
\end{tabular}

12. DISTRIBUTION/AVAILABILITY STATEMENT

Approved for public release; distribution unlimited

13. SUPPLEMENTARY NOTES

14. ABSTRACT

Although joint programs are typically formed to reduce costs, recent studies have suggested that they may actually be more costly than non-joint programs. In this paper, we explore this hypothesis using an in-depth case study of the NPOESS program. To study jointness, we apply a semi-quantitative framework that quantifies the complexity impacts of jointness and enables us to observe their evolution over time. In particular, we describe how jointness impacted the NPOESS program???by inducing technical and organizational complexity???and illustrate how the relationship between both complexity types enabled, sustained, and induced cost growth. We also explain the evolution of the program???s technical and organizational complexity by identifying five key technical decisions and collaborating agency interactions that increased complexity and cost. Finally, we conclude by noting that a key source of the NPOESS program???s cost growth was not jointness per say, but rather, was the result of a mismatch in the amount of jointness that was present in the program???s technical system but was absent in its managing organization.

15. SUBJECT TERMS

\begin{tabular}{|c|c|c|c|c|c|}
\hline \multicolumn{3}{|c|}{ 16. SECURITY CLASSIFICATION OF: } & 17. LIMITATION OF & 18. NUMBER & 19a. NAME OF \\
\hline $\begin{array}{c}\text { a. REPORT } \\
\text { unclassified }\end{array}$ & $\begin{array}{c}\text { b. ABSTRACT } \\
\text { unclassified }\end{array}$ & $\begin{array}{c}\text { c. THIS PAGE } \\
\text { unclassified }\end{array}$ & $\begin{array}{c}\text { Same as } \\
\text { Report (SAR) }\end{array}$ & 37 & \\
\hline
\end{tabular}


The research presented in this report was supported by the Acquisition Research Program of the Graduate School of Business \& Public Policy at the Naval Postgraduate School.

To request defense acquisition research, to become a research sponsor, or to print additional copies of reports, please contact any of the staff listed on the Acquisition Research Program website (www. acquisitionresearch.net). 


\section{Panel 13. Acquisition Jointness and Its Effects}

\section{Thursday, May 15, 2014}

9:30 a.m. 11:00 a.m.
Chair: LTG Joseph L. Yakovac Jr., USA (Ret.), Naval Postgraduate School, former Military Deputy to the Assistant Secretary of the Army (Acquisition, Logistics, \& Technology)

\section{The Decline and Fall of Joint Acquisition Programs}

Andrew Moore, Carnegie Mellon University William Novak, Carnegie Mellon University Mathews Collins, Carnegie Mellon University Jay Marchetti, Carnegie Mellon University Julie Cohen, Carnegie Mellon University

The Cost Impacts of Jointness: Insights From the NPOESS Program

Morgan Dwyer, Massachusetts Institute of Technology Zoe Szajnfarber, George Washington University Bruce Cameron, Massachusetts Institute of Technology Markus Bradford, Massachusetts Institute of Technology

Ed Crawley, Massachusetts Institute of Technology

Acquisition Risks in a World of Joint Capabilities: A Study of Interdependency Complexity

Mary Maureen Brown, University of North Carolina Charlotte 


\title{
The Cost Impacts of Jointness: Insights From the NPOESS Program
}

\begin{abstract}
Morgan Dwyer-is a PhD candidate in the Engineering Systems Division at MIT. Prior to MIT, Morgan worked at a systems engineer at Boeing Space and Intelligence Systems and held internships at Fermi-lab, NASA Marshall Spaceflight Center, and the Space Telescope Science Institute. Morgan received a BS in Astronomy \& Physics from Yale, an MS in Aeronautics from Stanford, and plans to defend her dissertation—which focuses on the cost impacts of jointness-in the fall of 2014. [mdwyer@mit.edu]
\end{abstract}

Zoe Szajnfarber-is an assistant professor of engineering management and systems engineering at the George Washington University. Her research seeks to understand the fundamental dynamics of innovation in technology-intensive organizations. She received her bachelor's degree in Engineering Science from the University of Toronto, a dual master's degree in Aeronautics \& Astronautics and Technology Policy and a PhD in Engineering Systems, all from MIT. [zszajnfa@gwu.edu]

Bruce Cameron-is a lecturer in engineering systems at MIT and a consultant on platform strategies. At MIT, Bruce ran the MIT Commonality Study, a 16-firm investigation of platforming returns. His current clients include Fortune 500 firms in high tech, aerospace, transportation, and consumer goods. He holds an undergraduate degree from the University of Toronto and graduate degrees from MIT. [bcameron@mit.edu]

Markus Bradford-is a junior economics major at MIT. He currently works as an undergraduate researcher at the MIT System Architecture Lab. His industry experience ranges from government and financial services and he is interested in project management in the technical space.

[mbrdfrd@mit.edu]

Edward Crawley-is a professor of aeronautics \& aeronautics and engineering systems at MIT. His research interests include system architecture, design, and decision authority in complex technical systems that involve economic and stakeholder issues. [crawley@mit.edu]

\section{Abstract}

Although joint programs are typically formed to reduce costs, recent studies have suggested that they may actually be more costly than non-joint programs. In this paper, we explore this hypothesis using an in-depth case study of the NPOESS program. To study jointness, we apply a semi-quantitative framework that quantifies the complexity impacts of jointness and enables us to observe their evolution over time. In particular, we describe how jointness impacted the NPOESS program-by inducing technical and organizational complexity-and illustrate how the relationship between both complexity types enabled, sustained, and induced cost growth. We also explain the evolution of the program's technical and organizational complexity by identifying five key technical decisions and collaborating agency interactions that increased complexity and cost. Finally, we conclude by noting that a key source of the NPOESS program's cost growth was not jointness per say, but rather, was the result of a mismatch in the amount of jointness that was present in the program's technical system but was absent in its managing organization.

\section{Introduction}

Jointness has numerous benefits: It enables government agencies to design for interoperability, to leverage a particular agency's unique technical capabilities, to benefit from mission and technical synergies, and to reduce a capability's overall cost. However, despite these benefits, recent studies suggest that joint programs may also have a critical disadvantage because they exhibit greater cost growth than non-joint programs (Brown, Flowe, Hamel, 2007; Cameron, 2011; Lorell et al., 2013; The National Research Council, 2011). This paper focuses on the cost of jointness so that future government decision- 
makers can make more informed cost-benefit trades when deciding to develop capabilities jointly.

To understand why joint programs incur greater cost growth, future decision makers require an improved understanding of how jointness has contributed to cost growth in the past. Our paper responds to this need by presenting the results of an in-depth case study of the National Polar-orbiting Operational Environmental Satellite System (NPOESS) program that specifically explores the relationship between cost growth and jointness. We begin by outlining the framework that we used to study jointness on NPOESS. Next, we review our results by presenting a brief history of the program, by identifying key decisions that induced technical and organizational complexity, and by describing the mechanisms by which complexity generated cost growth. Finally, we conclude by connecting the identified complexity mechanisms to the concept of jointness and by suggesting strategies that can be used to manage cost growth on future joint programs.

\section{A Framework to Assess the Impacts of Jointness}

In this paper, we define jointness in terms of a program's organizational and technical architecture. Crawley et al. (2004) define architecture as "an abstract description of the entities of a system and the relationships between those entities": essentially, a system's architecture is defined by its components and by the relationships between them. In our framework, we distinguish between two types of jointness: organizational and technical. A joint technical architecture is one that meets a diverse set of requirements from distinct and separate user groups. A joint organizational architecture is one that accommodates participation from more than one government agency. Given this definition, programs can be classified as either technically joint, organizationally joint, or as exhibiting both types of jointness; Figure 1 classifies several example programs according to these jointness types.

Importantly, joint architectures can also be defined by their ability to be disaggregated. Specifically, a joint technical architecture executes an aggregated set of requirements that could be alternatively executed by multiple distinct systems. Similarly, joint organizational architectures are also aggregated and can be disaggregated if government agencies develop systems independently instead of collaboratively. A current movement in the space acquisition community, which supports the disaggregation of previously joint programs, suggests two hypotheses that connect jointness to cost growth and motivate our focus on joint program architectures. The first hypothesis suggests that aggregated technical architectures are more complex than disaggregated ones and that when this complexity is not identified, budgeted for, and actively managed-it induces cost growth on joint programs (Air Force Space Command, 2013; Burch, 2012; Pawlikowski, Loverro, Cristler, 2001; Rendleman, 2009; Taverney, 2011). The second hypothesis suggests that aggregated organizational architectures are more complex than disaggregated ones and that this complexity induces and enables cost growth on joint programs (Bogdanos, 2005; Brown, Flowe, \& Hamel, 2007; Johnson, Hilgenberg, \& Sarsfield, 2001; Moore et al., 2013; The National Academies, 2011). Given these hypotheses, we suggest that in order to understand the relationship between jointness and cost growth, we must (1) identify the mechanisms within a joint program's technical and organizational architectures that induce complexity and (2) study the process by which these mechanisms induce, enable, and sustain cost growth over time. 


\begin{tabular}{|c|c|}
\hline $\begin{array}{l}\text { Organizational Disaggregation } \\
\text { Technical Disaggregation }\end{array}$ & $\begin{array}{c}\text { Organizational Disaggregation } \\
\text { Technical Aggregation } \\
\text { Space-Based Infrared System (SBIRS) } \\
\text { Earth Observing System (EOS) } \\
\text { Defense Weather Satellite System (DWSS) } \\
\text { Advanced Extremely High Frequency } \\
\text { (AEHF) Satellite System }\end{array}$ \\
\hline $\begin{array}{c}\text { Organizational Aggregation } \\
\text { Technical Disaggregation } \\
\text { Landsat }\end{array}$ & $\begin{array}{c}\text { Organizational Aggregation } \\
\text { Technical Aggregation } \\
\text { Space Radar }\end{array}$ \\
\hline Advanced Composition Explorer (ACE) & Global Positioning System (GPS) \\
\hline Joint Polar Satellite System (JPSS) & Fermi Gamma Ray Space Telescope \\
\hline $\begin{array}{c}\text { Geostationary Operational Environmental } \\
\text { Satellite (GOES) }\end{array}$ & $\begin{array}{c}\text { Narional Polar-orbiting Operational } \\
\text { Environmental Satellite System (NPOESS) }\end{array}$ \\
\hline
\end{tabular}

\section{Figure 1. Example Programs Classified in Terms of Type of Jointness}

To study jointness in this way, we developed a semi-quantitative framework (Dwyer \& Szajnfarber, 2014) to represent joint program architectures using design structure matrices (DSMs; Eppinger \& Browning, 2012) and to quantify their complexity using metrics. Specifically, our framework defines two separate DSMs to represent a program's organizational and technical architectures and the complexity mechanisms within them and calculates two metrics that quantity the complexity inherent within each architecture. To apply this framework to study NPOESS, we define the program's architectures during six epochs-or periods of time when those architectures were unique and stable-and observe the evolution of complexity and its relationship to cost growth over time.

In our framework, we define technical complexity to be a function of the components of a system and the interactions between those components. Three types of technical complexity mechanisms are represented in our technical architecture DSM and included in our complexity metric, which serves as a proxy for the program's lifecycle cost, corrected for complexity. We define the three types of technical complexity mechanisms as

- Design complexity, which is a function of the technical maturity of each component,

- Process complexity, which is a function of the constraints or conflicting requirements that are imposed during the component development process, and

- Architectural complexity, which is a function of the interactions and relationships between components.

Next, we represent the program's organizational architecture by mapping relationships between organizational components, which are distinct sub-units within the organization that include the government agencies, user communities, program offices, and contractors. The two relationships that are critical to our definition of organizational complexity are 
- Mission responsibility, which indicates that an organizational component is responsible for delivering a technical system that executes its specified mission, and

- Decision authority, which indicates that an organizational component it is able to make and sustain effective decisions.

We define organizational complexity to be a function of the misalignment of mission responsibility and decision authority and factors that erode decision authority. We suggest that organizational complexity is related to cost growth because as an organization's complexity increases, it becomes more difficult for the organization to make effective and efficient decisions; as a result, complex organizations are more likely to enable, sustain, and induce cost growth. To assess organizational complexity, we use a metric that quantifies the misalignment of mission responsibility and decision authority and the erosion of decision authority.

To apply our framework to study the impacts of jointness on NPOESS, we collected a mix of qualitative and quantitative data. In total, we interviewed 57 representatives from the program and collected over 75 hours of semi-structured qualitative interview data (Eisenhardt \& Graebner, 2007; Yin, 2009). As recommended by Eisenhardt \& Graebner (2007) we sampled interviewees from multiple levels in the program's organizational hierarchy and we triangulated (Yin, 2009) our data using over 150 primary and secondary source documents. In the following sections, we summarize the conclusions of our analysis; for a complete description of our data-set and a mapping between each of our subsequent conclusions and its supporting data, please refer to Dwyer (2014).

\section{A Brief History of the NPOESS Program}

NPOESS was a collaboration between the Department of Defense (DoD), the National Oceanic and Atmospheric Administration (NOAA), and the National Aeronautics and Space Administration (NASA) that was intended to develop a constellation of environmental monitoring satellites for low-Earth orbit; NPOESS was established in 1994 and cancelled - due to cost growth, schedule delays, and management issues (The White House, 2010) - in 2010. The NPOESS system met the requirements of multiple user groups and was developed collaboratively by all three agencies; as such, NPOESS is an important example of both organizational and technical jointness. To observe the evolution of the program's complexity and cost over time, we defined six epochs and represented the program's organizational and technical architectures for each; the DSMs created for each epoch are contained in Dwyer (2014). Key events during each epoch include:

Epoch A (1994-1996): NPOESS was established by converging NOAA's Polar Operational Environmental Satellite (POES) program and the DoD's Defense Meteorological Satellite Program (DMSP) and was motivated by the desire to save $\$ 1.3$ billion in lifecycle costs (Gore, 1993). These cost estimates assumed that the NPOESS technical architecture would be composed of a constellation of three operational spacecraft with modest performance improvements over POES and DSMP. To manage the development of the NPOESS system, an Integrated Program Office (IPO) was established and staffed by all three agencies. An Executive Committee (EXCOM), which was composed of the NASA Deputy Administrator, the Under Secretary of Commerce for Oceans and Atmosphere, and the Under Secretary of Defense for Acquisition and Technology, was also created to provide policy guidance and to approve changes to the program's baseline.

Epoch B (1996-1999): The NPOESS system requirements were defined in the Integrated Operational Requirements Document (IORD-I). To meet these new requirements, 
four new instruments were added to the technical architecture and the existing instruments evolved to more closely resemble the higher performance instruments in NASA's Earth Observing System (EOS). Additionally, according to its "optimized convergence" acquisition strategy, the program office managed multiple risk reduction contracts for each of its key instruments but delayed selecting a prime contractor. NOAA and the DoD shared financial responsibility for funding these contracts, which were managed according to DoD acquisition processes; although NASA participated in the IPO, the EXCOM, and the requirements development process, it did not officially levy requirements on the system and provided no funding.

Epoch C (1999-2002): The NASA-managed NPOESS Preparatory Project (NPP) was established to execute two missions: (1) to provide risk reduction for key sensors and (2) to provide data continuity for several climate science variables. To execute NPP's dual missions, the IPO managed and funded the development of three of its critical sensors while NASA's separate NPP program office procured and funded a spacecraft bus, developed and funded an additional sensor, funded NPP launch costs, and managed the system's integration. To meet the needs of the program's new climate science users, the IORD's requirements were updated to enhance instrument performance and one additional sensor was added.

Epoch D (2002-2005): The prime contract was awarded and all of the instrument and algorithm contracts that were previously selected and managed by the IPO were transferred to the prime; shortly after this transfer, the program's cost estimates began to grow.

Epoch E (2005-2007): The program's cost estimates increased so significantly they breached the Nunn-McCurdy threshold and the program had to undergo certification. As a result, four instruments and two spacecraft were cancelled and a Program Executive Officer (PEO) was added to streamline decision-making between the IPO, the NPP program office, and the EXCOM.

Epoch F (2007-2010): Two instruments were added back to the technical architecture and despite the new PEO-authority structure, management challenges persisted and cost estimates continued to grow until the program's cancellation in 2010.

By representing the program's organizational and technical architectures during each epoch, quantifying their complexity, and normalizing each complexity metric by the complexity of the predecessor POES and DMSP architectures, we are able to draw several conclusions about the evolution of the program's costs. First, Figure 2 plots our technical complexity metric (a proxy for lifecycle cost) alongside the program's own lifecycle cost estimate; this illustrates that the program's technical complexity increased after Epoch A, while its cost estimates_-particularly after Epoch B-continued to remain low. This suggests that the changes to the technical architecture between Epochs $\mathrm{A}$ and $\mathrm{C}$ added a significant amount of design, process, and architectural complexity that was under-estimated and under-managed by the program until Epoch D, when its cost estimates began to increase. As noted in Figure 2, during these early epochs, we suggest that organizational complexity enabled the program's technical costs to be under-estimated and under-managed. After Epoch D, when the program's costs were clearly no longer a function of its technical architecture, we suggest that additional cost growth was induced by organizational complexity. Using these relationships between complexity and cost growth, we organize our subsequent discussion according to the following principles:

- First, we suggest that technical decisions induced cost growth by introducing design, process, and architectural complexity into the NPOESS technical 
architecture. Technical decisions are those that were made within the NPOESS organization but were responsive to the collaborating agencies' interactions with each other and with the NPOESS program offices.

- Second, agency interactions with each other and with the NPOESS program offices induced organizational complexity by misaligning decision authority and mission responsibility and by eroding decision authority within the NPOESS organization. Agency interactions were often formally documented in policy directives that were implemented by the NPOESS program; however, unofficial agency interactions also induced organizational complexity.

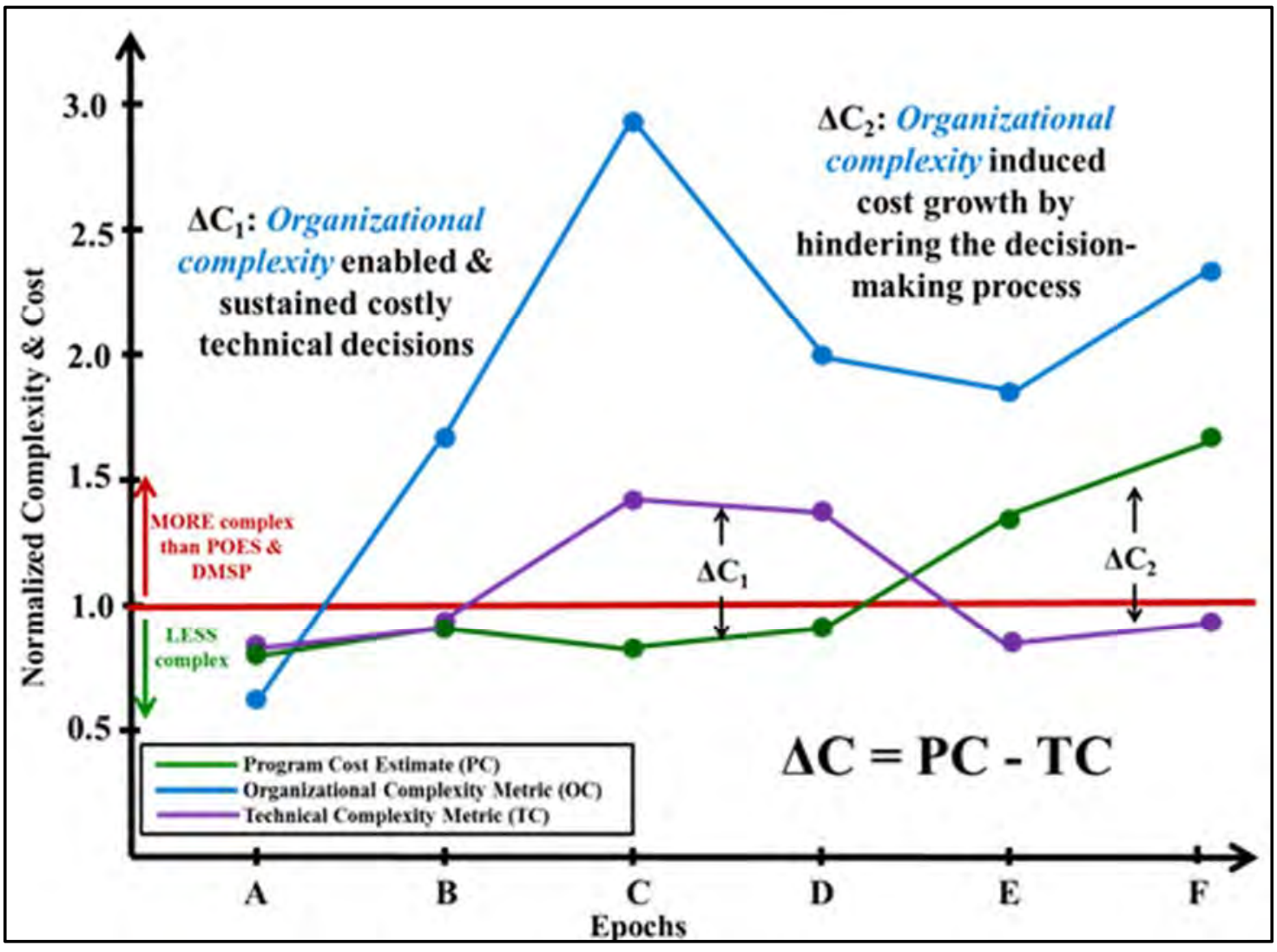

Figure 2. Evolution of and Relationship Between Complexity and Cost

We suggest that organizational and technical complexity are related because as the NPOESS organization's complexity increased, it enabled and sustained costlier technical decisions. We also suggest that organizational complexity is directly related to cost growth because organizational complexity hindered the program's decision-making process by making less efficient. In the following sections, we define the decisions and interactions that introduced complexity into the NPOESS technical and organizational architectures and describe the mechanisms by which these decisions and interactions generated complexity and ultimately enabled, sustained, and induced cost growth.

\section{Decisions That Induced Technical Complexity}

Figure 3 plots the evolution of technical complexity and identifies the five major decisions that induced it. As noted above, we define technical complexity to be a function of 
a system's components and component interactions and to consist of three types of mechanisms: design, process, and architectural. The mechanisms that were injected into the NPOESS technical architecture after each decision are captured in the DSMs-shown in miniaturized form - and by the value of the complexity metric that was calculated for each epoch. As shown, a majority of the system's complexity was induced by early technical decisions and even after the Nunn-McCurdy certification-a process intended to reduce complexity-complexity continued to increase until the program's cancellation. In this section, we review these major technical decisions and discuss the design, process, and architectural complexity that they induced.

Decision 1 (Define the IORD-I): The first complexity inducing decision was to define the system's requirements in the IORD-I; as shown in Figure 3, this decision increased the system's complexity to a level that was only slightly less than the pre-convergence POES and DSMP systems. Interviewees described the IORD-I as a concatenation of each agency's unique or driving requirements; as such, the IORD-I induced both architectural and design complexity. First, the IORD-I induced architectural complexity by requiring that four new instruments be added to the technical architecture so that several agency-unique requirements could be met. For example, a radar altimeter was added primarily to meet Navy requirements and a solar irradiance and earth radiation budget sensor were added to meet NOAA-unique requirements; importantly, because none of these sensors were hosted by either heritage POES or DMSP they ultimately increased NPOESS's architectural complexity compared to these heritage programs. The fourth sensor that was added after the IORD-I was a cross-track scanning microwave sounder; although only a conical microwave sounder with many of the same channels had been baselined during Epoch $A$, after the IORD-I accepted many agency-unique requirements, NOAA enforced its requirement for cross-track, rather than conical, microwave sounding.

The IPO further exacerbated the complexity impacts of its multi-instrument technical architecture by deciding to host all of those instruments on a common, aggregated spacecraft bus. This decision induced architectural complexity because many of the instruments adversely interacted with one another mechanically, electromagnetically, or optically; these interactions generated extra cost because they had to be managed and mitigated by the program. For example, the conical microwave sounder induced a significant amount of jitter, the radar altimeter was a lone active instrument hosted alongside a manifest of passive and highly sensitive instruments, and the solar irradiance sensor's preference for a sun-pointing viewing geometry conflicted with the remaining instruments' requirement for a nadir-pointing view. In these and other examples, the program's costs increased as greater engineering effort was required to manage and mitigate architectural complexity. 


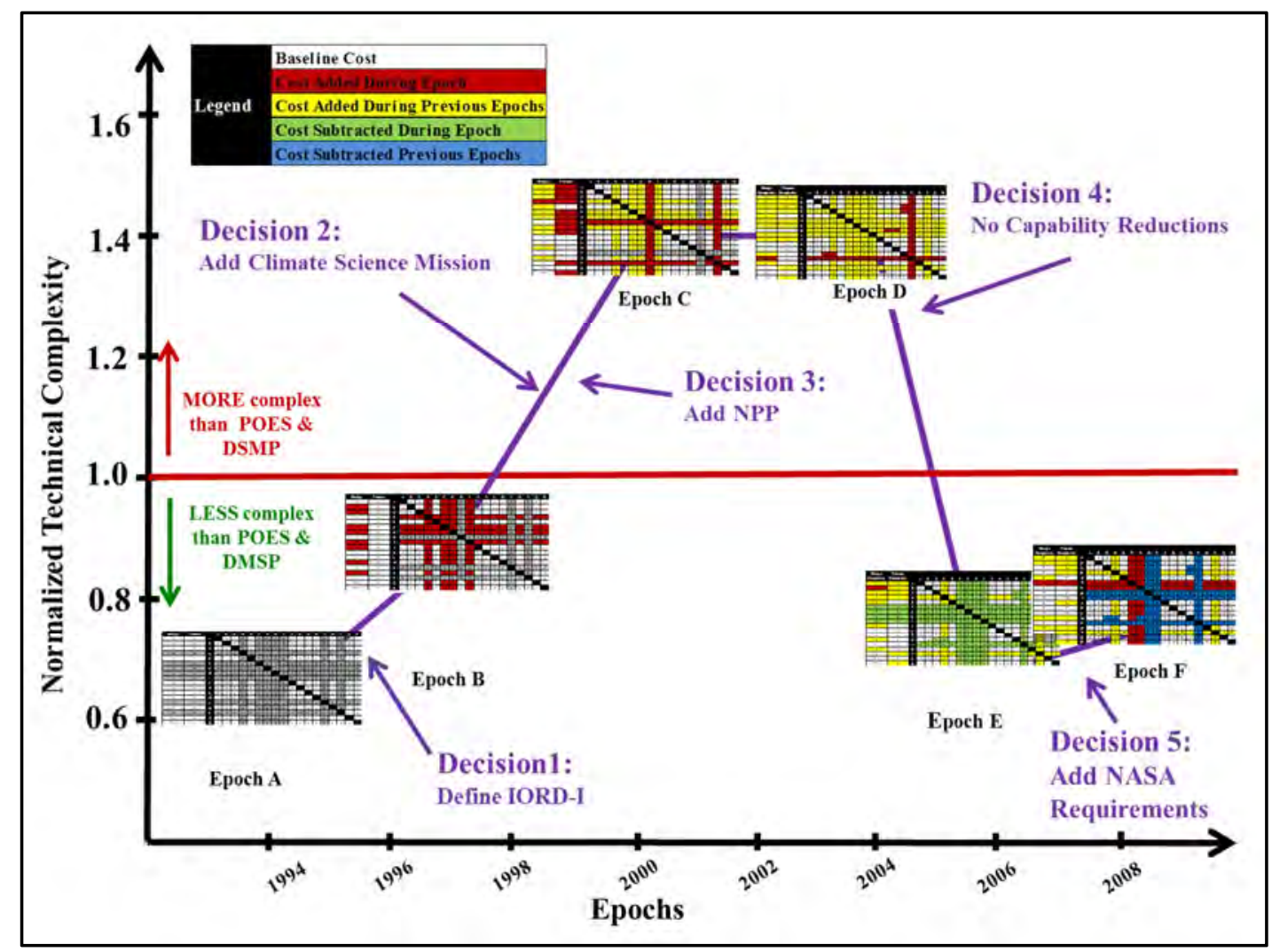

Figure 3. Decisions That Induced Technical Complexity During the NPOESS Program

In addition to architectural complexity, the IORD-I induced design complexity by levying each agency's unique or driving requirements on single instruments; the primary impact of this decision was that neither agency's heritage instruments were capable of meeting the IORD's joint requirements and that a significant amount of new design effort was required. The best example of instrument design complexity is the Visible Infrared Imaging Radiometer Suite (VIIRS) which had to meet NOAA's driving requirement for high radiometric accuracy and the DoD's need for high resolution imagery. To meet these and other requirements, an instrument design based off of NASA's Moderate Resolution Imaging Spectroradiometer (MODIS) was proposed. However, to meet the DoD's requirement for low-light imagery, a new scanning technique had to be incorporated into the MODISheritage design and MODIS's visible and near-infrared focal plane arrays had to be combined. The program under-estimated the design and cost impacts of these changes since late in VIIRS's development, modulated infrared background and scattered light problems - both of which could be traced back to these deviations from MODIS-heritagenecessitated a re-design that delayed the program's schedule.

Decision 2 (Add Climate Science Mission): While the complexity induced by IORD-I was substantial, as shown in Figure 3, the next two technical decisions-to add climate science to the program's mission manifest and to establish the NPP program-induced the greatest amount of design, architectural, and process complexity into the system. As noted in the section on the history of the NPOESS Program, these decisions are related, since climate science was not an official NPOESS objective until the formation of the dual mission risk-reduction/climate science NPP program.

New climate science requirements were formalized in a revision to the IORD-I that added long-term stability requirements to 18 environmental data records (EDRs), tightened 
horizontal resolution requirements on 18 EDRs, and enhanced requirements for uncertainty, accuracy, and precision to 20 others; for reference, there were 55 total EDRs in the IORD-II. The changes to the IORD increased instruments' design complexity since modifications and new non-recurring development effort was required to meet its new requirements. For example, VIIRS - which also had its specific sensor requirements document altered to insure that its design was backwards compatible with MODIS-evolved from 14 to 21 channels as a result of adding climate science requirements to the program (Dwyer, 2014).

In addition to changing the IORD, the new climate science mission altered the program's calibration and validation (cal/avl) plans. Prior to Epoch C, the IPO's cal/val plans focused on validating operational data products that were produced rapidly and in compliance with the system's data latency specification; however, once the climate science mission was added, a separate NASA cal/val team was established to ensure that data products were also suitable for scientific research. Although in many cases the dual teams' roles were complementary, as detailed by The National Research Council (2000), climate science $\mathrm{cal} / \mathrm{val}$ adds additional, distinct requirements to the operational process. Thus, the addition of the climate science mission induced process complexity by adding new requirements and by increasing the amount of government oversight of the $\mathrm{cal} / \mathrm{val}$ process.

Decision 3 (Add NPP): The formation of the NPP program itself also induced additional process complexity in two ways. First, since NASA's NPP program office was responsible for integrating the program's instruments onto the spacecraft bus and for mission systems engineering, it levied NASA requirements on instruments that were procured under DoD contracts, using DoD standards. These NASA requirements induced process complexity when systems engineers had to reconcile both sets of requirements during V\&V-an exercise whose cost was not included in the program's initial estimates. Second, the unclear prioritization between the NPP program's dual missions induced a significant amount of process complexity by injecting uncertainty and conflict into the instrument $V \& V$ process.

The cost impact of NPP's dual missions was most visible when its instruments experienced anomalies or failures during analysis or test because the process used to resolve issues for a risk reduction mission fundamentally conflicts with the process used for a non-risk reduction (i.e., a climate science) mission. Specifically, on a risk reduction mission, if a program encounters an issue with an instrument, it identifies the issue's rootcause and implements a corrective action for the next system; importantly, any corrective action that is implemented on the risk-reduction flight article is subject to cost and schedule constraints, which enjoy a higher priority than instrument performance or functionality. Alternatively, on a non-risk reduction mission, full instrument performance and functionality is paramount and necessary to achieve the mission's objectives. Therefore, when issues are encountered during instrument test or analysis, corrective actions that restore instrument performance are prioritized —or least weighted equally—to actions that preserve the program's cost and schedule. 


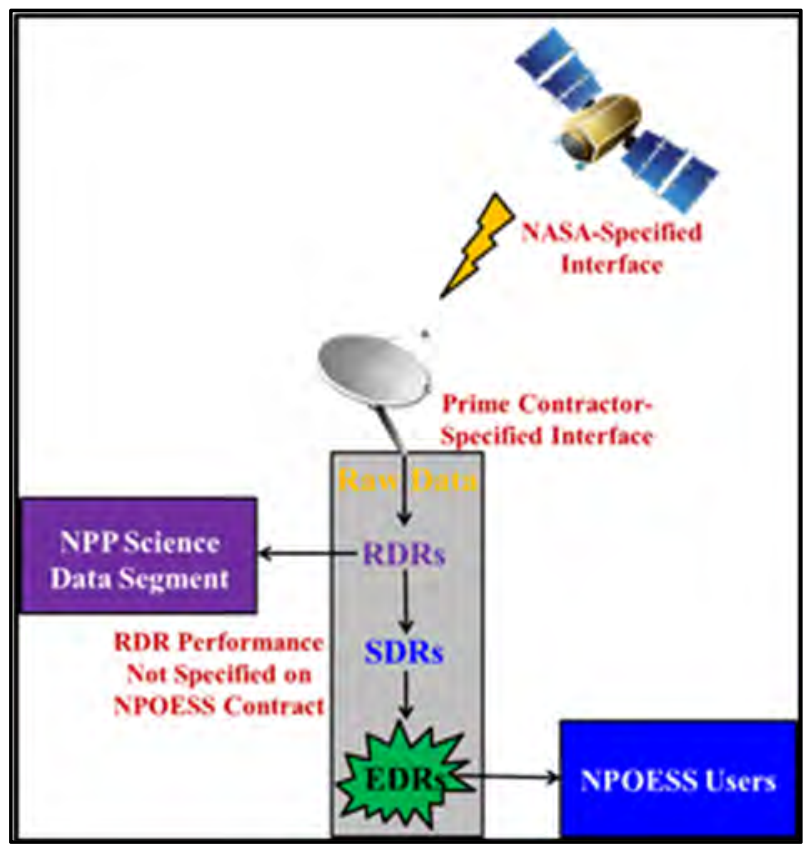

Figure 4. NPP's Interfaces With NPOESS IDPS and Ground System

These philosophical differences generated conflict and uncertainty when issues were encountered during instrument analysis and test on the NPP program. The resulting process complexity induced cost by reducing the speed at which the program could make decisions. Instead of implementing corrective actions consistent with one mission or the other, numerous options were debated and either the most costly and conservative option was selected or the issue was elevated to program management-which in several cases involved the EXCOM. Obviously, because this conflict and uncertainty was not anticipated, the decision to add the NPP program induced a significant amount of process complexity and cost.

Finally, the NPP program also induced architectural complexity by creating two new interfaces between the NPP and NPOESS systems that not only had to be managed by the program, but also levied new requirements on the system. First, as shown in Figure 4, although the NPP spacecraft interfaced with the NPOESS ground system, interface definition was not formally included on either the spacecraft or the ground system providers' contracts. As a result, the process by which the contractors defined this critical interface was slow and cumbersome, since negotiations had to include both the ground system and NPP spacecraft contractors, the NPOESS prime contractor, and each government agency which held the contracts separately.

The interface between the NPP Science Data Segment (SDS) and the Interface Data Processing Segment (IDPS) of the NPOESS ground system also induced architectural complexity and cost by creating a new and previously unspecified interface within the data processing system. As shown in Figure 4, the IDPS processed data through two intermediate stages before delivering EDRs: the only data products which had performance attributes that were specified on the NPOESS contract. However, the SDS interfaced with the IDPS at an intermediate data product, its Raw Data Records (RDRs), which it then transformed into Level $1 \mathrm{~b}$ data products and Climate Data Records (CDRs) that supported scientific research. However, because RDR performance was not specified on the NPOESS contract, this new interface became a mechanism for requirements creep when climate science users needed the RDRs to be more carefully controlled and characterized so that 
they could appropriately manage the performance of the climate science data products that were derived from them.

Decision 4 (No Capability Reductions): While the first three technical decisions injected the greatest amount of complexity into the NPOESS technical system, there were also architectural and process impacts from the later decisions shown in Figure 3. The fourth decision-to maintain the system's capability despite cost growth and budget constraintsinduced architectural complexity when delays and cost growth on one instrument induced lifecycle cost growth on others. For example, when VIIRS's costs grew but the program's budget remained fixed, instead of cancelling sensors to free up funding, the IPO reduced funding and extended the schedule of the system's lower priority components. Of course, this decision ultimately increased the lifecycle cost of these components and of the system as a whole.

Decision 5 (Add NASA Requirements): Finally, the fifth decision-to unofficially levy NASA requirements on components of the operational NPOESS system-added unnecessary process complexity by generating conflict between DoD and NASA requirements. As noted previously, components of the NPOESS system were procured according to DoD standards; however, interviewees noted that during the later years of the program, NASA representatives began requesting that components of the operational system (i.e., not NPP) meet NASA standards as well. As in the NPP program, this generated unnecessary requirements conflict, delayed decisions, and thus, induced cost growth.

With the five decisions that induced technical complexity and cost identified, we now focus our discussion on understanding why the NPOESS organization made such costly decisions. The disconnect between technical complexity and the program's reported cost estimates (shown previously in Figure 2) suggests that the organization made costly technical decisions because it underestimated and under-managed those decisions' design, process, and architectural complexity impacts. According to the principles we set forth earlier in the paper (in A Brief History of the NPOESS Program section), we assert that these costly technical decisions were enabled and sustained by organizational complexity and that organizational complexity itself also induced additional cost growth. Finally, we also suggest that agency interactions both with the program and each other were responsible for injecting complexity into the NPOESS organizational architecture. With these suppositions, we organize the next section by identifying the agency interactions that induced organizational complexity and illustrate how that complexity enabled, sustained, and induced cost growth.

\section{Interactions That Induced Organizational Complexity}

Figure 5 plots the evolution of organizational complexity and identifies the five major agency interactions that induced it. As noted previously, we define organizational complexity to be a function of the misalignment of mission responsibility and decision authority and factors that erode decision authority. Both misalignment and authority erosion factors are captured in the DSMs—shown in miniaturized form—and by the value of the complexity metric that was calculated for each epoch. In this section, we review the agency interactions that induced organizational complexity and describe how this complexity enabled and sustained the costly technical decisions discussed in a previous section (Decisions That Induced Technical Complexity) and induced further cost growth by hindering the organization's decision-making process.

Interaction 1 (Delegate Decision Authority to the EXCOM): First, Figure 5 identifies Interaction 1 as the foundational policy directive-the agencies' Memorandum of Agreement (MOA) - that delegated each agency's decision authority to the EXCOM; as shown, this 
directive affected organizational complexity throughout the NPOESS program. Although the purpose of the EXCOM was to provide a venue for the agencies to make decisions collaboratively, its decision authority was eroded throughout the program. For example, the EXCOM did not meet frequently enough or with a full quorum of its members, to make effective decisions (GAO, 2005, 2009). Furthermore, although each agency delegated its decision authority to the EXCOM, the agencies did not fully delegate their mission responsibilities; as a result, the agencies continued to independently oversee the program. This action generated extra work for the IPO, which had to be responsive to three agencies' requests for information. Unfortunately, this extra oversight did not affect positive change, since the agencies' only mechanism for making decisions was through the EXCOM. Thus, we observed that a misalignment of mission responsibility and decision authority enabled and sustained cost growth by preventing agencies from unilaterally taking action to reduce cost and induced it by generating extra oversight and by delaying decisions that had to be made collaboratively by the EXCOM.

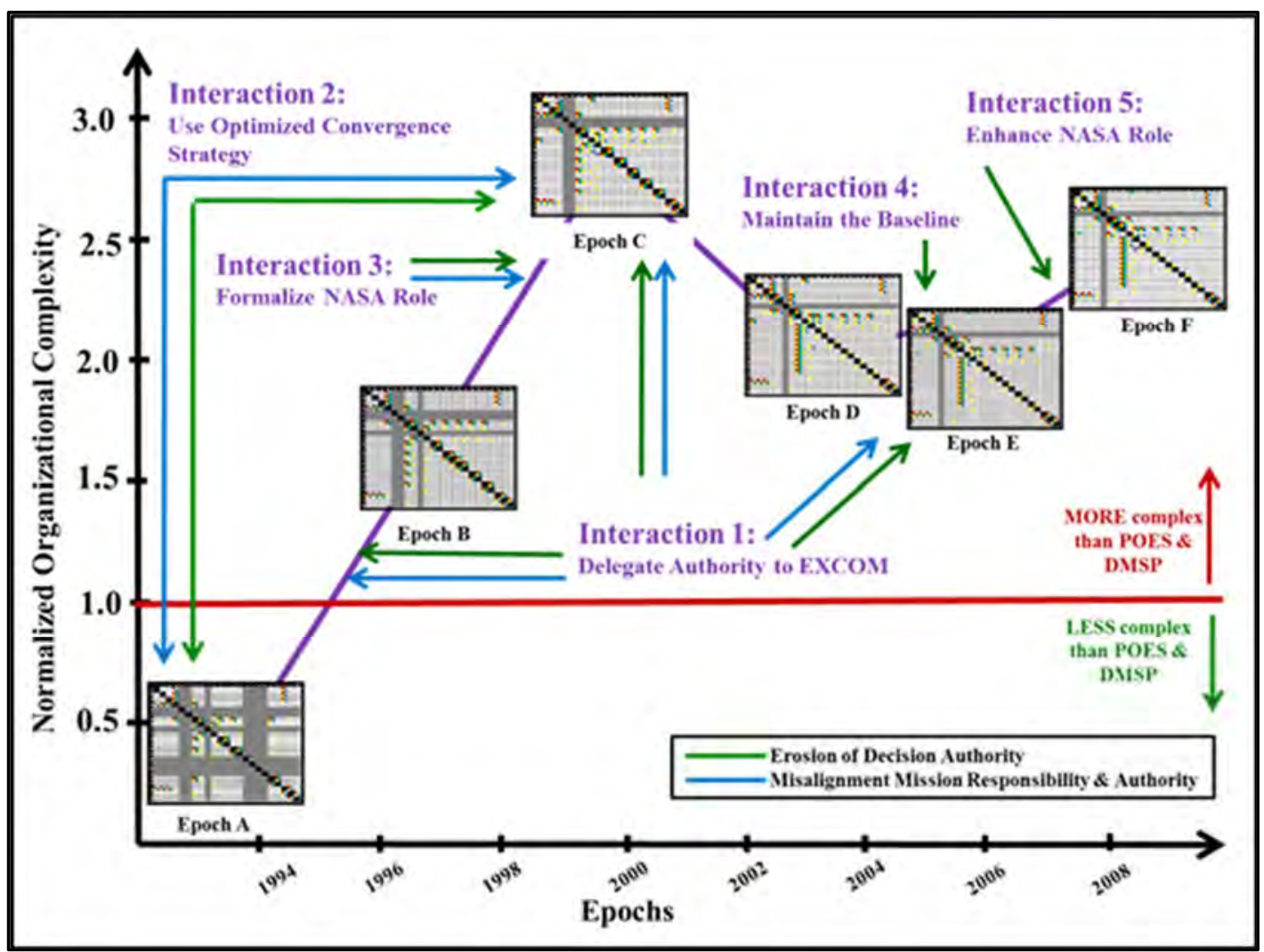

Figure 5. Agency Interactions That Induced Organizational Complexity During the NPOESS Program

Importantly, the MOA that formed the NPOESS program did not establish the EXCOM as the organization's central decision-making component. We suggest that the complexity of the organizational hierarchy beneath the EXCOM-and particularly the misalignment of mission responsibility and decision authority-forced the EXCOM to play a decision-making role that was never intended by the MOA. Thus, while the EXCOM itself did contribute to organizational complexity and to the program's costs, we argue that it was the complexity of the organizational architecture beneath the EXCOM that most significantly 
affected complexity and cost growth; the agency interactions that induced this complexity are identified below.

Interaction 2 (Use Optimized Convergence Strategy): As shown in Figure 5, the second agency interaction, to delay the first satellite need-date and to constrain early funding profiles, resulted in a directive to use the optimized convergence acquisition strategy and ultimately, a program that was more complex than the separate POES and DMSP organizations. Unlike traditional acquisition strategies, which concurrently select all of a system's contractors, the optimized convergence strategy issued multiple, multi-year, and separate risk reduction contracts for the system's key components. This strategy enabled the agencies to reduce the program's early funding and to adjust its schedule to better align with the final launches of POES and DMSP.

Despite these advantages, optimized convergence induced organizational complexity in two ways. First, it eroded decision authority by weakening the organization's financial responsibility for its decisions. Specifically, until Epoch D, sensor vendors were still in competition to win final contracts; as a result, until those contracts were awarded, sensor vendors had a greater incentive to manage their proposed costs rather than their proposals' potential design complexity. Furthermore, in accordance with its Total System Performance (TSPR)-like ${ }^{1}$ contracts, the IPO relied heavily on contractor-produced cost estimates when it assessed its overall cost; consequently, the IPO's earliest estimates were skewed by the competitive environment that was fostered by optimized convergence. As a result, the quality of their technical decisions was poor, since the IPO was unable to appropriately assess each decision's cost. For example, the climate science mission was added before the sensor vendors were on contract; as a result, when the IPO requested a requirements change, sensor vendors reported minimal cost impacts in the hopes that doing so would enable them to win the final contract. This enabled early instrument design complexity to be under-estimated during the program's early epochs.

The optimized convergence strategy also enabled architectural complexity to be under-estimated and under-managed because it misaligned mission responsibility and decision authority. Specifically, although the IPO intended to award a TSPR-like prime contract that would assign mission responsibility for managing and integrating all components of the NPOESS system to a single company, that company was not selected until Epoch D. As a result, during the program's early epochs, its prospective prime contractors had no direct decision authority over the components for which they would ultimately be responsible. Interviewees reported that prior to Epoch D, the prime contractor had limited insight into the instruments' development and had no authority to require changes or to request additional information directly from the sensor vendors. As a result, once the prime contractor was selected and the sensor contracts transitioned from the government to the prime, the prime contractor discovered that instrument designs were less mature than the complexity and cost assumptions that it used in its proposal.

Given this immaturity, instrument mass and power continued to grow well into Epoch D; for example, between Epochs C and E, VIIRS's mass and power grew by $34 \%$ and $48 \%$, respectively (Dwyer, 2014). With such growth on VIIRS and other instruments, the prime

${ }^{1}$ Officially, NPOESS contracts were Shared System Performance Responsibility (SSPR); however, our data suggests that, in practice, there was little difference between SSPR and TSPR. 
contractor unexpectedly struggled to close spacecraft mass and power budgets. Similarly, mechanical and electromagnetic interferences between instruments do not appear to have been actively managed until Epoch $\mathrm{D}$, when the prime contractor was finally awarded decision authority over the components for which it was responsible.

Interaction 3 (Formalize NASA's Role): As shown in Figure 5, the third agency interaction-to formalize NASA's role in the larger NPOESS program by establishing its authority over NPP and the program's new climate science mission-had the greatest impact on organizational complexity because of how significantly it misaligned decision authority and mission responsibility. Figure 7 illustrates one example of the misalignment that was induced by the formation of NPP using the VIIRS sensor vendor's relationship to surrounding organizational components. As shown, there was a mission responsibility relationship between the VIIRS sensor vendor and the NPP program office: in order to execute NASA's climate science mission, the VIIRS sensor vendor had to develop an instrument that met the needs of NPP's climate science users. Importantly, despite this relationship, there was no contractual, or decision authority relationship, between NPP and the sensor vendor. This left NPP with two options to execute its mission responsibility: (1) to influence decisions informally at the contractor level or (2) to elevate issues to the organizational component that held decision authority over both the NPP program office and the VIIRS sensor vendor.

By attempting to influence the VIIRS sensor vendor's decisions informally, the NPP program office ultimately eroded the decision authority that the prime contractor and the IPO held over VIIRS. As noted above, eroded decision authority contributed to organizational complexity and in this particular example, decision authority was eroded in two ways. First, NPP provided a significant amount of technical support to the sensor vendor. While the value of this added technical capability should not be under-stated, it also eroded the prime contractor and the IPO's decision authority by second-guessing their decisions. This interaction was exacerbated by a second factor that eroded decision authority: the fact that NPP was not financially responsible for its decisions. As noted previously, the IPO funded three of NPP's instruments, while NASA's NPP program office funded the spacecraft and launch. The misalignment of mission and financial responsibility for NPP's instrument's caused the NPP program office to inappropriately weigh risk vice cost when making technical decisions-particularly those that involved the prioritization of NPP's dual missions. 


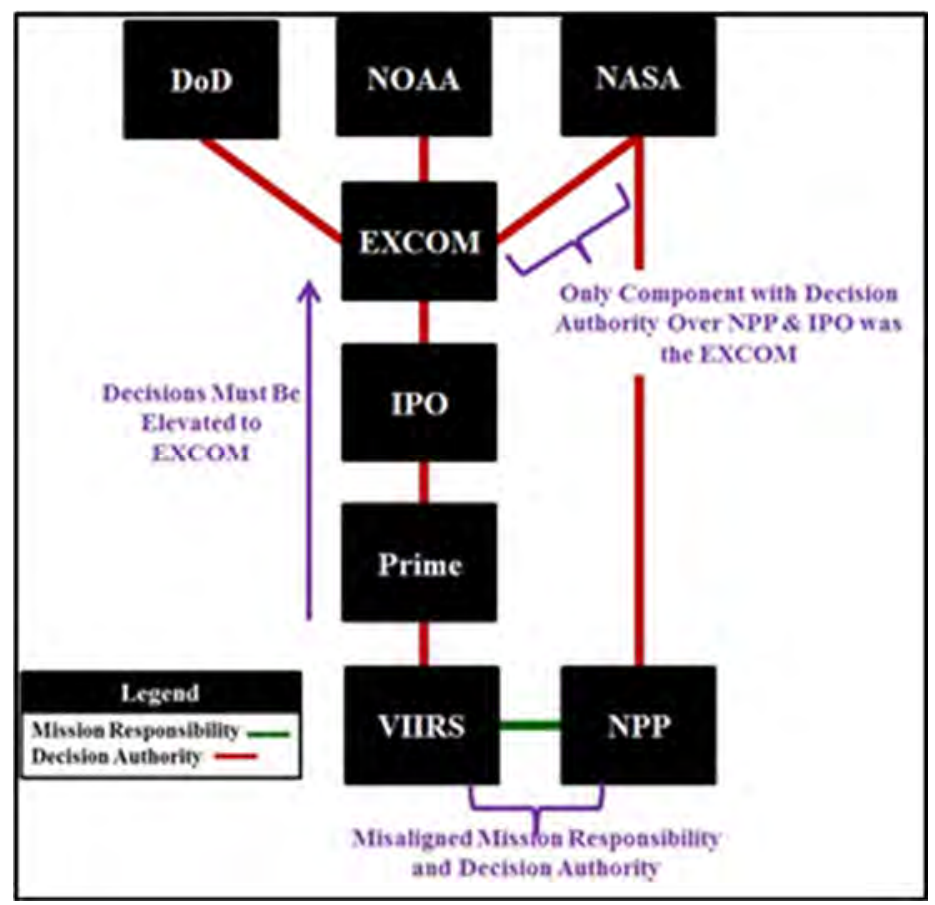

Figure 6. A Portion of the NPOESS Decision Authority Structure That Illustrates a Critical Misalignment of Decision Authority \& Mission Responsibility Between Sensor Vendor \& the NPP Program Office

As described in the section titled Decisions That Induced Technical Complexity, the impact of eroded decision authority at the contractor level was that decisions were delayed as multiple options were debated, the most costly and conservative option was selected, or decisions were elevated for arbitration. In the latter case, as shown in Figure 6, the only component that held decision authority over both NPP and the IPO was the EXCOM. Thus, elevating decisions induced further cost growth, since the contractors' decisions were stalled as issues were raised through each agency's organizational hierarchy so they could be discussed by agency leaders at the EXCOM.

Interaction 4 (Maintain the Baseline): While initial agency interactions had the greatest impact on the program's organizational complexity, as shown in Figure 5, the remaining interactions also enabled and induced cost growth. The fourth interaction, between the agencies' user communities, hindered the program's ability to alter its technical baseline; this enabled the architectural complexity that was discussed previously (in Decisions That Induced Technical Complexity section)—when cost growth on one instrument induced lifecycle cost growth on others. Interaction 4 also induced organizational complexity by eroding the IPO's decision authority: because essentially any member of the IPO's user advisory councils could veto proposals that reduced the system's capability, the IPO struggled to make these decisions. Importantly, agency management also failed to intervene by directing capability reductions or by providing the funding that was necessary to support the system's numerous capabilities.

Interaction 5 (Enhance NASA's Role): As shown in Figure 5, after the NunnMcCurdy certification process added a PEO, organizational complexity decreased: indeed, the purpose of the PEO was to improve the alignment of mission responsibility and decision authority between NPP and the IPO and to reduce the number of decisions that were elevated to the EXCOM. However, the fifth agency interaction-which enhanced NASA's 
influence both in the program and in NOAA's National Environmental Satellite, Data, and Information Service (NESDIS)—eroded the PEO's decision authority and ultimately rendered the position ineffective. Thus, the misalignment of mission responsibility and decision authority between NPP and the IPO continued to induce non-technical cost growth as decisions were delayed or elevated to the EXCOM.

The above discussion illustrates how significantly agency interactions, that were external to the program itself, impacted NPOESS's complexity and cost. Each agency interaction injected complexity into the NPOESS organization that enabled, sustained, and induced costly technical decisions. Although we do not speculate on why the program's agency collaborators took these actions, we suggest that by observing how agency actions have impacted programs' organizational and technical architectures in the past, we can inform and improve actions in the future. In the case of the NPOESS program, agency interactions' induced organizational complexity that weakened technical decision making from the EXCOM through the instrument sub-contractors and hindered the organization's ability to make anything but the costly technical decisions that it did.

\section{Assessing the Impacts of Jointness}

Now that we have reviewed the technical decisions and agency interactions that induced technical and organizational complexity throughout the NPOESS program, we return to our definition of jointness and connect the identified complexity mechanisms to the concept of technical and organizational aggregation. Three types of technical aggregation induced the complexity and cost growth that was discussed in an earlier section (Decisions That Induced Technical Complexity). First, we observed that requirements aggregation in the IORD - specifically, that each agency levied their unique or driving requirements on the system-induced design complexity in the program's instruments because neither agencies' heritage instruments were capable of meeting the program's joint requirements. This outcome suggests that when a program's requirements are defined jointly, they can induce cost growth by necessitating new technology development. Since the cost of developing new technology is highly uncertain and the program invested in multiple uncertain development projects with a limited budget, overruns on one project induced lifecycle cost growth on others. This suggests that when an aggregated architecture contains numerous technically immature components, not only can the components themselves induce cost growth, but so too can the resource dependencies between them; as a result, the risk of cost growth on an aggregated program is not only a function of the number of immature components but also a function of the number of potential interactions between them. Finally, we also observed requirements aggregation by noting that multiple agency standards were levied on the system and that by doing so, the agencies induced process complexity by generating extra and unnecessary work for the engineers who were tasked with reconciling disparate technical standards. This suggests that unless joint programs accept and consistently utilize one agency's technical standards, costs will be induced when the program is forced to meet both.

Second, we observed that spacecraft aggregation, or assigning multiple instruments to share the same spacecraft bus, induced architectural complexity when instruments interfered electromagnetically, mechanically, and optically. We also observed that spacecraft aggregation induced design complexity in the spacecraft bus itself, since the prime contractor had to re-design critical aspects of its standard bus. These outcomes suggest that technical aggregation can induce both design and architectural complexity that should be actively managed so that the program can appropriately budget for the cost of this complexity or consider alternative disaggregated architectures that reduce it. Third, we observed that mission aggregation induced process complexity because NPP's dual 
missions were not prioritized. This suggests that unless systems execute single missions, their multiple missions need to be clearly prioritized at the outset of the program.

Like the technical architecture, several of the complexity mechanisms in the organizational architecture can be attributed to aggregation. For example, we noted that NPP's additional source of technical capability eroded contractor and IPO decision authority by second-guessing decisions on instruments like VIIRS. This suggests that if multiple sources of technical capability converge at a single organizational component (like the VIIRS sensor vendor), those sources should be aligned with single source of decision authority. We also noted that delegating agency decision authority to the EXCOM induced complexity because the EXCOM's decisions were infrequent and its decision authority was misaligned with the agencies' individual mission responsibilities. We suggest that this source of complexity may be inherent to all joint programs, since individual agencies' mission responsibilities are often derived from separate congressional committees. Thus, future joint programs' budgets should include additional funding to facilitate the extra government oversight that is required to enable each agency to individually fulfill its mission responsibilities.

However, most importantly, we noted that the majority of the NPOESS organization's complexity was a result of the disaggregation, rather than the aggregation, of critical relationships between organizational components. Specifically, although the NPOESS organization was tasked to develop an aggregated technical system, responsibility and authority for that system were separated across numerous and distinct components of the NPOESS organization. For example, the separation of NPP's mission and financial responsibility for the program's instruments impeded cost-risk trades and ultimately strained the agencies' collaboration. Additionally, the separate IPO and NPP program offices fractionated decision authority and crippled decision-making since technical issues raised by vendors for shared IPO-NPP sensors could only be resolved by the EXCOM. Finally, the optimized convergence strategy separated the prime contractor, which would ultimately hold financial and mission responsibility for the system's instruments and interfaces, from the decision authority to manage the system until 10 years into the program, after most of the critical cost-inducing decisions had already been made.

\section{Conclusions}

So was organizational and technical aggregation-or jointness-to blame for the NPOESS program's cost growth? The answer, of course, is both yes and no. In terms of technical jointness, requirements and mission aggregation undoubtedly induced design and process complexity that contributed to the program's costs. While these requirements and missions were aggregated by different users and agencies, the resulting requirements creep was similar to other government acquisition programs and is not necessarily unique to jointness. Spacecraft aggregation also induced architectural complexity, but it is unclear whether it would have been more cost effective to disaggregate the NPOESS program's multiple instruments onto different platforms. As shown in Figure 2, in the program's earliest epochs, the aggregated spacecraft architecture was actually less costly than the disaggregated POES and DMSP systems. Using these observations from the NPOESS program, we recommend that to mitigate the potential cost growth that can be induced by technical aggregation, future joint programs should:

- Recognize that joint requirements hinder a program's ability to leverage individual agencies' heritage capabilities and budget for the technology development that is necessary to integrate all of those capabilities into a single system. 
- Utilize common standards or invest in non-recurring system engineering effort to reconcile different standards.

- Budget for interactions between instruments and for the cost of spacecraft aggregation.

In terms of organizational jointness, it was the separation of financial responsibility, mission responsibility, and decision authority that contributed most significantly to the program's costs. Some of the organization's complexity-like that induced by the program's optimized convergence strategy and TSPR-like contracts-was not a result of jointness. However, the complexity induced by the separation of the NPP and IPO program offices, the ability of the program's user community to veto all capability-reducing decisions, and the erosion of the PEO's authority, were all induced by the joint nature of the program. Using these observations from the NPOESS program, we recommend that future joint programs should

- Award contracts early in the system's lifecycle and concurrently for all of the system's components.

- Fully integrate responsibility, authority, and technical capability into a single program office.

- Institute a PEO-like authority structure over the user community to enable capability reductions.

Most importantly_particularly for government agencies that are contemplating the merits of future aggregated or disaggregated programs-our analysis suggests that the greatest source of complexity and cost on the NPOESS program was not directly function of aggregation, but rather, was a result of the mismatch between the NPOESS program's aggregated technical but disaggregated organizational architectures. Specifically, although the NPOESS organization developed an aggregated technical system, it did so with two disaggregated NPP and IPO program offices. As discussed above, the disaggregated program offices both misaligned responsibility and authority, eroded the IPO's decision authority, and were responsible for much of the technical complexity that was induced by the addition of NPP and the climate science mission.

Given this observation, we suggest that both aggregated and disaggregated programs can be executed cost-effectively as long as the program's organizational and technical architectures match. Specifically, we recommend that

- Aggregated technical architectures should be developed by fully aggregated organizations with single program offices.

- And that disaggregated technical architectures should also be developed by single program offices and that importantly, these offices should be disaggregated from one another.

For example, if the DoD disaggregates its follow-on to DMSP into three separate systems that focus on visible-infrared, microwave, and space weather data, it should establish three separate program offices to manage their development and should minimize the organizational relationships between them. Of course, our recommendation is not without policy risks. With numerous capabilities disaggregated across multiple technical systems, agency leaders may see opportunities for efficiency and cost-savings if management responsibilities are shared across related program offices. Similarly, with numerous capabilities aggregated into a single technical system, agency collaborators may prefer to divide responsibilities within an aggregated organization while continuing to share decision authority. In both cases, the tendency towards mismatching a program's 
organizational and technical architecture can result in the type of complexity and cost growth that we observed on the NPOESS program. However, as on NPOESS, we suggest that this complexity is ultimately induced by agency interactions, which we hope will be informed and improved by this and future analyses of joint programs.

\section{References}

Air Force Space Command, (2013). Resiliency and Disaggregated Space Architectures: White Paper. Retrieved from http://www.afspc.af.mil/shared/media/document/AFD130821-034.pdf

Bogdanos, M.F. (2005) Joint Interagency Cooperation: The First Step. Joint Force Quarterly, Issue 37. Retrieved from http://www.au.af.mil/au/awc/awcgate/jfq/0437.pdf

Brown, M.M., Flowe, R.M. and Hamel, S.P. (2007). The Acquisition of Joint Programs: The Implications of Interdependencies. CROSSTALK: The Journal of Defense Software Engineering. Retrieved from http://www.dtic.mil/dtic/tr/fulltext/u2/a487683.pdf

Burch, R. (2012) OPS: Disaggregation \& Diversification of U.S. MILSATCOM. Milsat Magazine. Retrieved from: http://www.milsatmagazine.com/story.php?number=510061234

Cameron, B. (2011) Costing Commonality: Evaluating the Impact of Platform Divergence on Internal Investment Returns (Doctoral Dissertation). Retrived from MIT DSpace, http://hdl.handle.net/1721.1/68511, 2011

Committee on the Assessment of Impediments to Interagency Cooperation on Space and Earth Science Missions; The National Research Council. (2011) Assessment of Impediments to Interagency Collaboration on Space and Earth Science Missions. Washington, DC: The National Academies Press.

Crawley, E.F., DeWeck, O., Eppinger, S., Magee, C., Moses, J., Seering, W. et al. (2004) The Influence of Architecture in Engineering Systems - Engineering Systems Monograph. Cambridge, MA: MIT Engineering Systems Division, Retrieved from http://esd.mit.edu/symposium/pdfs/monograph/architecture-b.pdf

Dwyer, M. (2014) The Cost of Jointness: Insights from Environmental Monitoring Satellites in Low-Earth Orbit (Doctoral Dissertation, expected fall 2014)

Dwyer, M., \& Szajnfarber, Z. (2014). A Framework to Assess the Impacts of Jointness. Paper presented at the 4th International Engineering Systems Symposium 2014, Hoboken, NJ.

Eisenhardt, K.M., Graebner, M.A. (2007). Theory-Building from Cases: Opportunities and Challenges. Academy of Management Journal. 19(1), 33-52.

Eppinger, S., Browning, T. (2012). Design Structure Matrix Methods and Applications. Cambridge, MA: The MIT Press.

Gore, Al. (1993). Creating a Government that Works Better and Costs Less: Third Report of the National Performance Review. Retrieved from http://www.nsf.gov/pubs/stis1993/npr93a/npr93a.txt

GAO. (2005). Polar-Orbiting Operational Environmental Satellites: With Costs Increasing and Data Continuity at Risk, Improvements Needed in Tri-Agency Decision Making. (GAO-06-249-T). Washington, DC: U.S. Government Printing Office.

GAO. (2009). Polar-Orbiting Operational Environmental Satellites: Technical Problems, Cost Increases, and Schedule Delays Trigger Need for Difficult Trade-off Decisions. (GAO09-546). Washington, DC: U.S. Government Printing Office. 
Johnson, D.J., Hilgenberg, G.H., \& Sarsfield, L.P. (2001) Policy Issues and Challenges for Interagency Space Systems Acquisition. Santa Monica, CA: RAND, National Security Division.

Lorell, M.A., Kennedy, M., Leonard, R.S. , Munson, K., Abramzon, S., An. D.L. et al. (2013). Do joint fighter programs save money?, Santa Monica, CA: RAND Corporation, 2013.

Moore, A.P., Novak, W.E., Cohen, J.B., Marchetti, J.D., Collins, M.L. (2013). The Joint Program Dilemma: Analyzing the Pervasive Role that Social Dilemmas Play in Undermining Acquisition Success. Paper presented at the 10th Annual Acquisition Research Symposium Acquisition Management. Monterey, CA.

Pawlikowski, E., Loverro, D., Cristler, T. (2013) Space: Disruptive Challenges, New Opportunities, and New Strategies. Strategic Studies Quarterly. Retrieved from http://www.au.af.mil/au/ssq/2012/spring/pawlikowski.pdf

Moore, A.P., Novak, W.E., Cohen, J.B., Marchetti, J.D., Collins, M.L. (2013). The Joint Program Dilemma: Analyzing the Pervasive Role that Social Dilemmas Play in Undermining Acquisition Success. Paper presented at the 10th Annual Acquisition Research Symposium Acquisition Management. Monterey, CA.

National Research Council. Issues in the Integration of Research and Operational Satellite Systems for Climate Research: Part II. Implementation. Washington, DC: The National Academies Press, 2000.

Rendleman, J.D. (2009). Why SmallSats? Presented at AIAA Space 2009 Conference \& Exposition. Pasadena, CA.

Taverney, T. (2011) Resilient, Disaggregated, and Mixed Constellations. The Space Review, August 2011. Retrieved from: http://www.thespacereview.com/article/1918/1

The White House (2010). Restructuring the National Polar-orbiting Operational Environmental Satellite System [Press release]. Retrieved from http://www.whitehouse.gov/sites/default/files/npoess decision fact sheet 2-1-10.pdf

Yin, R.K. (2009) Case Study Research: Design and Methods, 4th ed. Los Angeles: SAGE.

\section{Acknowledgements}

The authors would like to extend their sincerest thanks to the interviewees who shared their time, memories, and technical and management expertise with us during the research process. We should also like to thank the MIT-Sandia Excellence in Engineering Graduate Fellowship and the Skolkovo Institute of Science and Technology for their financial support of this work. 
ACQUISITION RESEARCH PROGRAM GRADUATE SCHOOL OF BUSINESS \& PUBLIC POLICY NAVAL POSTGRADUATE SCHOOL 555 DYER ROAD, INGERSOLL HALL MONTEREY, CA 93943 


\title{
The Cost Impacts of Jointness:
}

Insights from the NPOESS Program

\author{
Morgan Dwyer \\ Zoe Szajnfarber, Bruce Cameron, Markus Bradford, Edward Crawley \\ Massachusetts Institute of Technology
}




\section{Introduction to NPOESS}
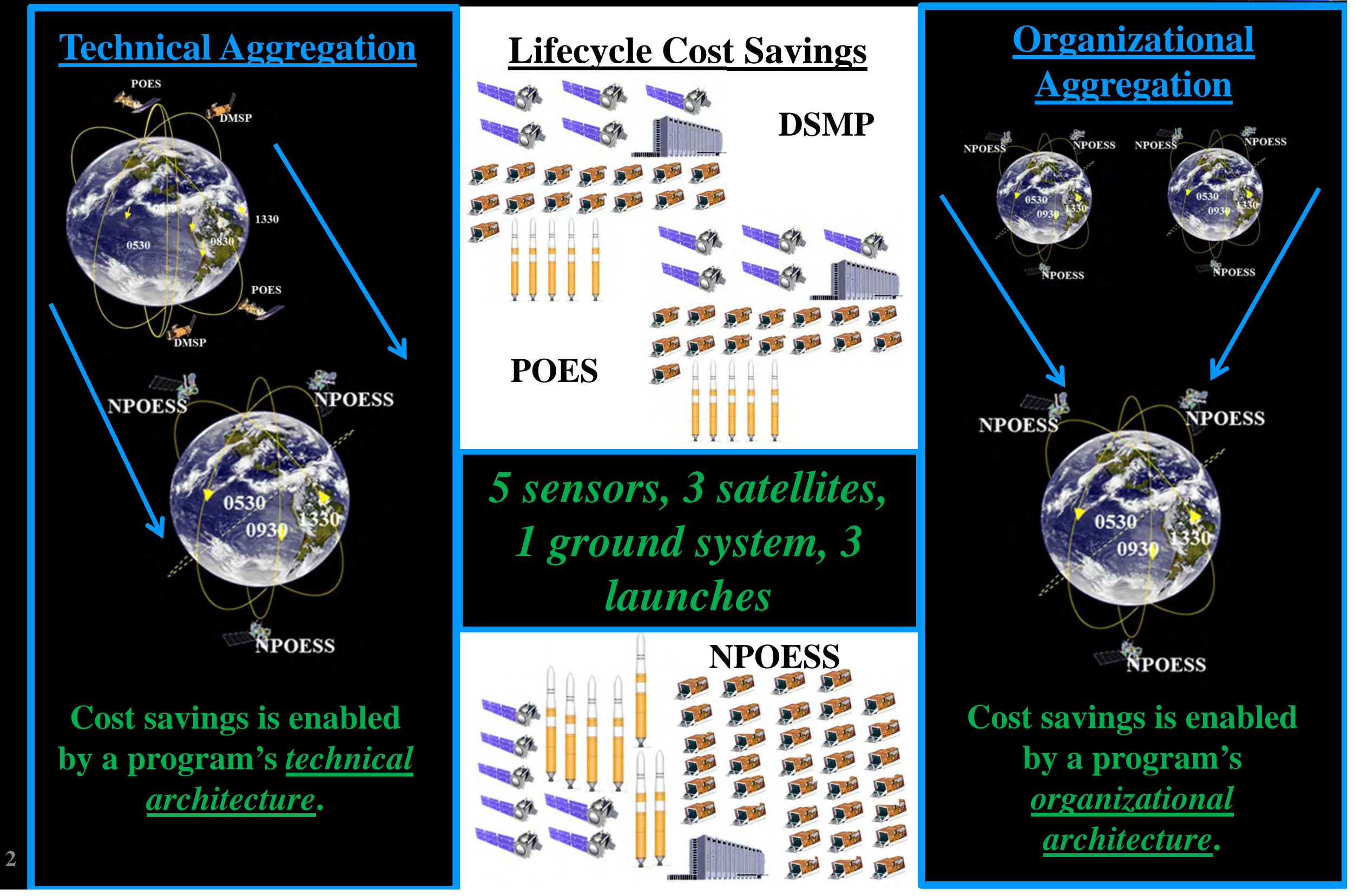


\section{Potential Impacts of Jointness}

Technical \& Organizational Disaggregation

- Disaggregate missions to reduce technical complexity \& save costs (Burch 2012)

- Only collaborate when there are very compelling reasons to do so (NRC 2011)

\section{4}

Organizational Aggregation

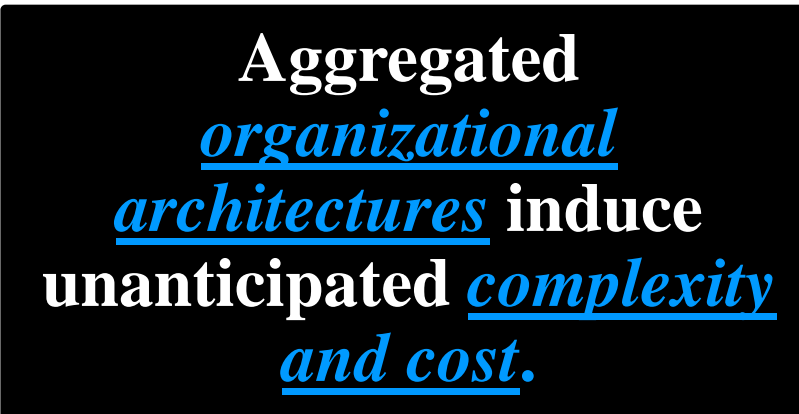

\section{Technical Aggregation}

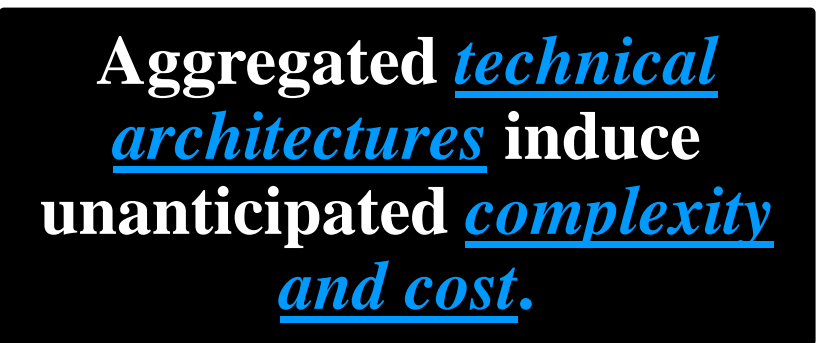

Technical \& Organizational Aggregation

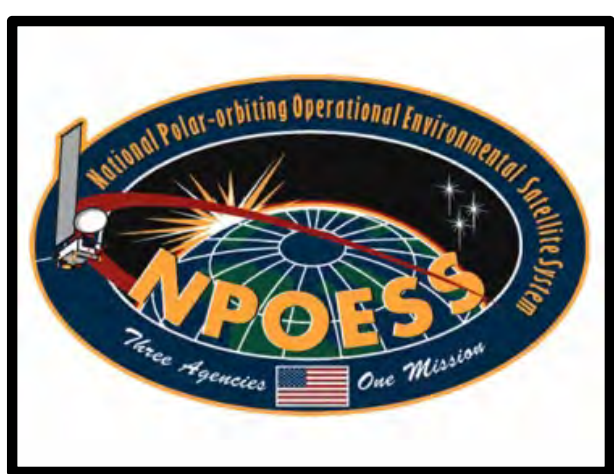

NPOESS 


\section{A Framework to Assess Impacts}

\section{Technical Complexity:}

A function of the components of a system \& the interactions between them.

\section{the program's organizational \&
nnical architectures \&
ntify their complexity organizational \&
technical architectures \&
quantify their complexity organizational \&
technical architectures \&
quantify their complexity \\ Approach: Represent}

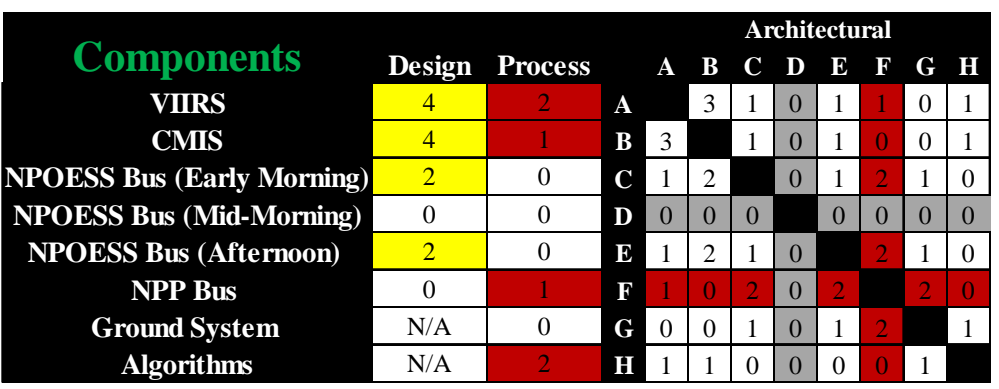

\section{Organizational Complexity:}

A function of the misalignment of mission responsibility \& decision authority and factors that erode decision authority.

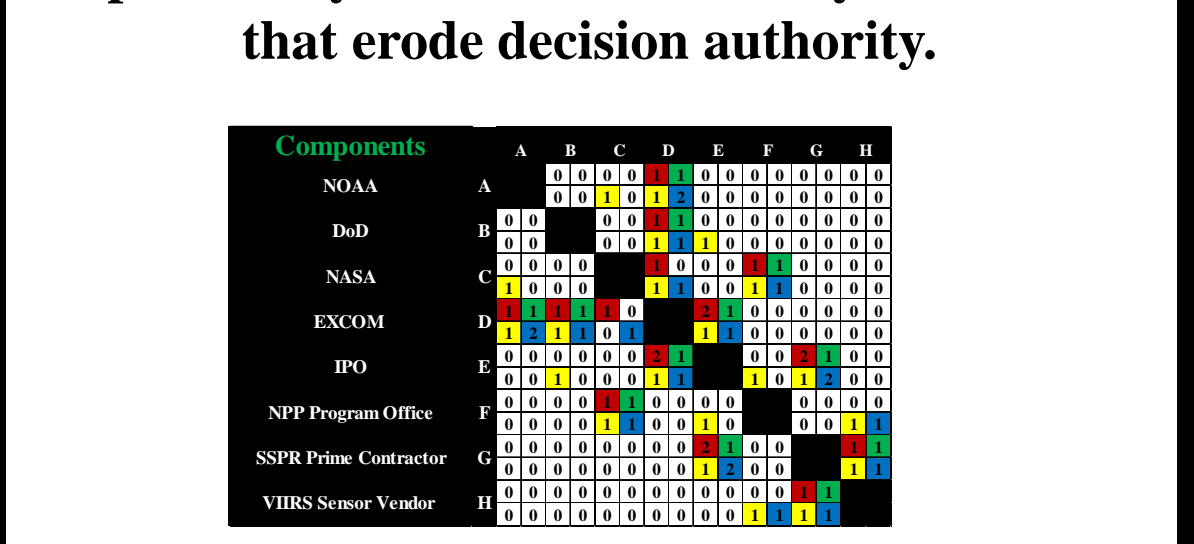
Goal: Observe the
evolution of complexity
\& its relationship to cost
Goal: Observe the
evolution of complexity
\& its relationship to cost
Goal: Observe the
evolution of complexity
\& its relationship to cost growth, technical
decisions \& agency interactions over time.

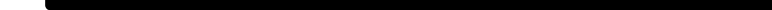




\section{Evolution of Technical Complexity}

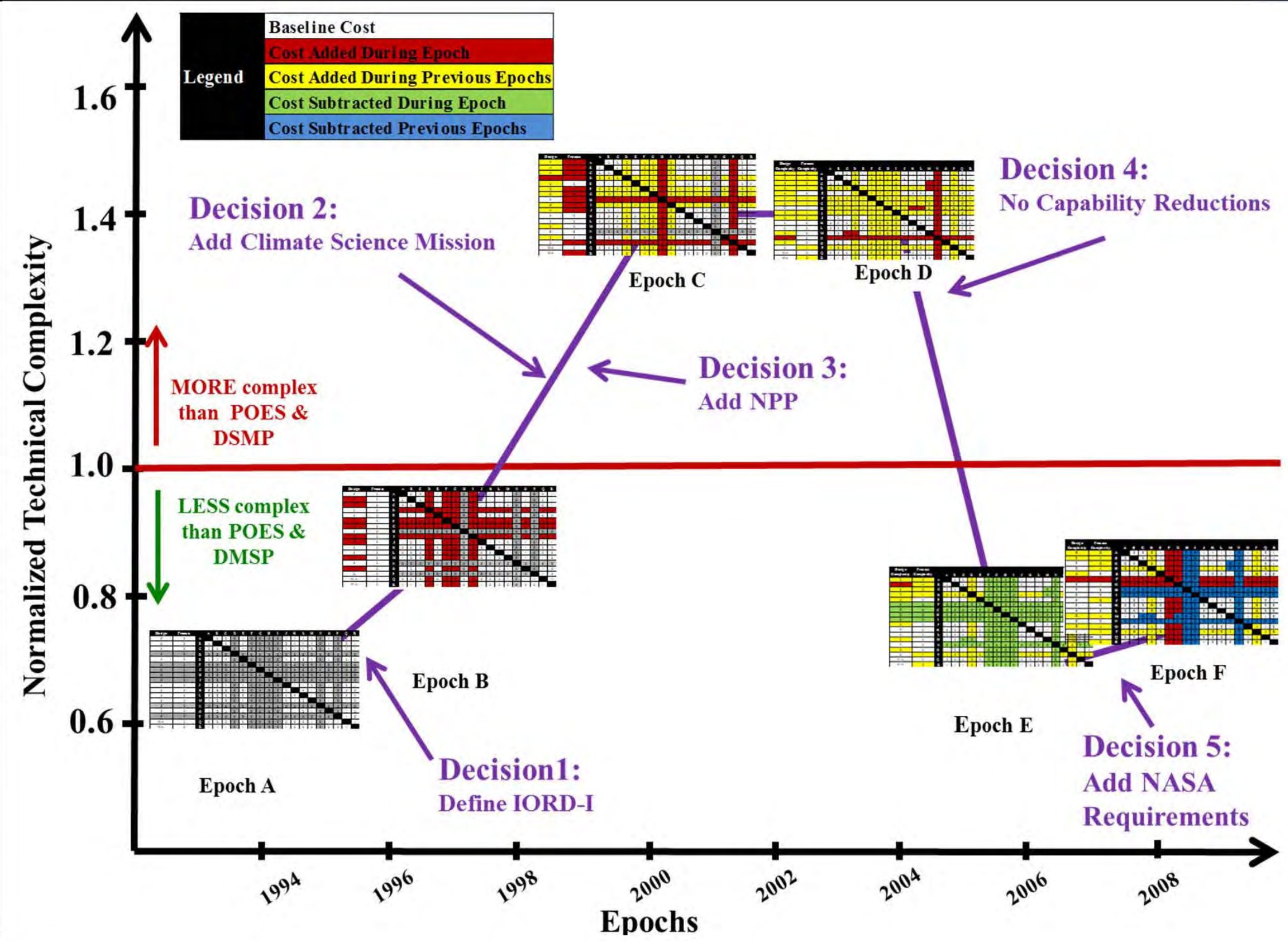




\section{Evolution of Organizational Complexity}

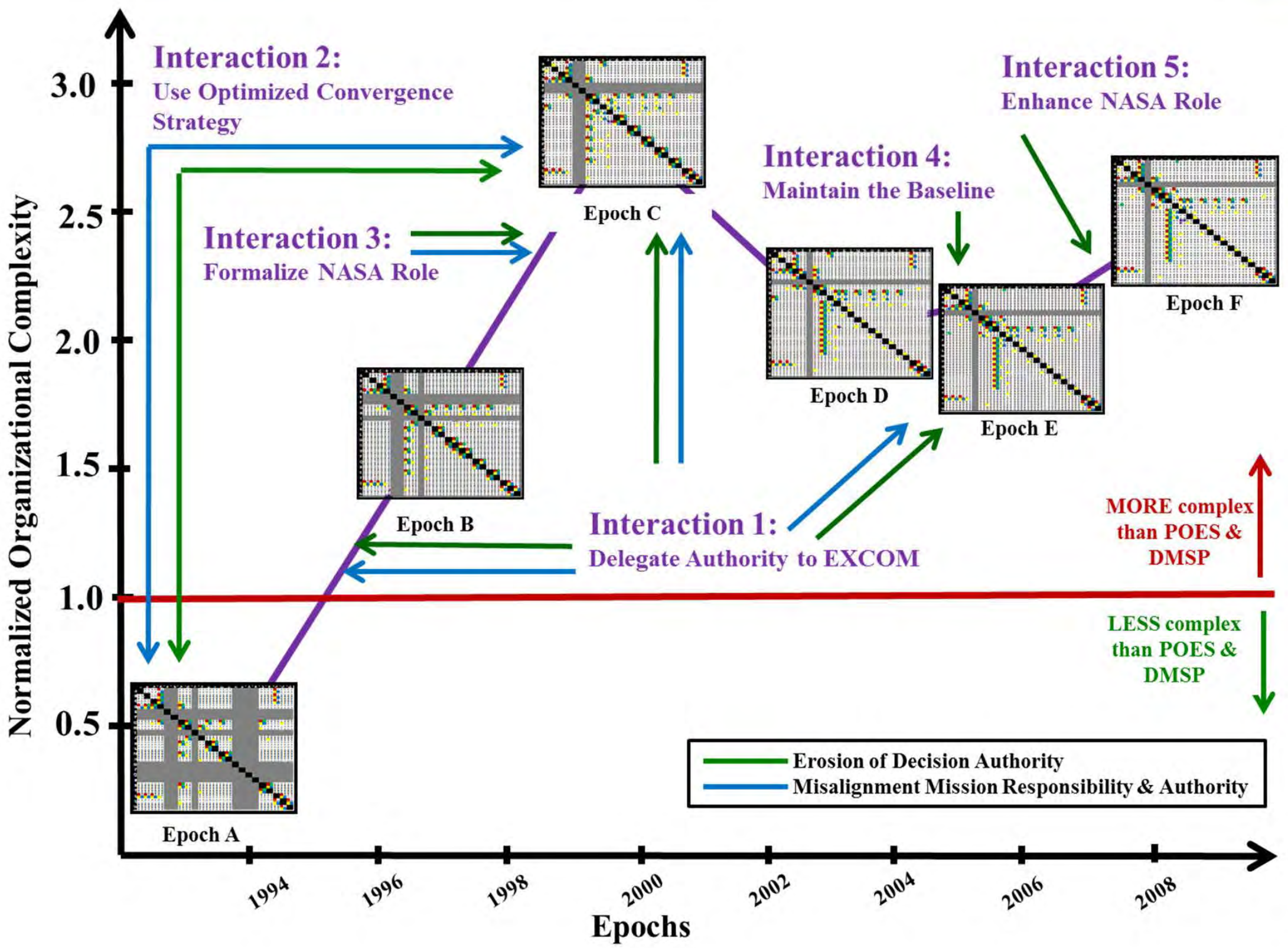




\section{Technical Costs of Jointness}

- Requirements Aggregation

- Joint requirements necessitated technology development

- Investing in multiple technology development projects increased budget uncertainty

- Multiple agency engineering standards had to be negotiated and reconciled

- Spacecraft Aggregation

- Interactions between instruments induced additional non-recurring instrument, bus, and SE costs

- Mission Aggregation

- Despite its dual mission identity, NPP was developed as an operational mission

Technical aggregation induced non-recurring cost growth but had the potential to save lifecycle costs

if it had been effectively managed.

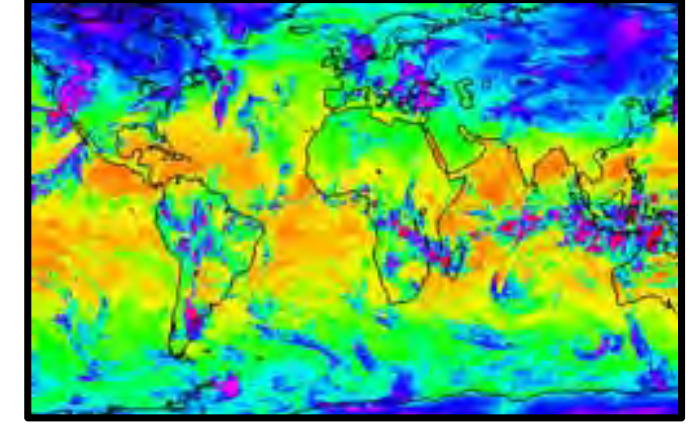

CrIS (Image: NASA)

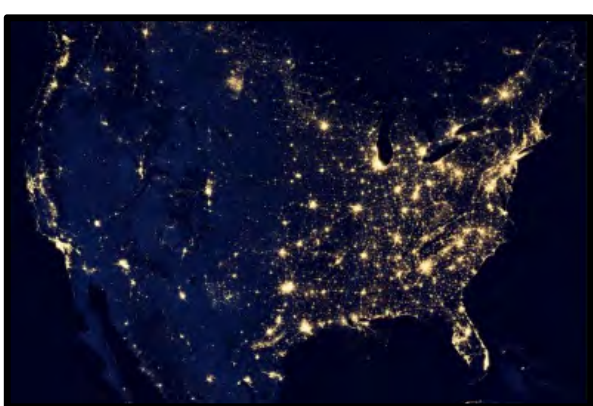

VIIRS (Image: NASA)

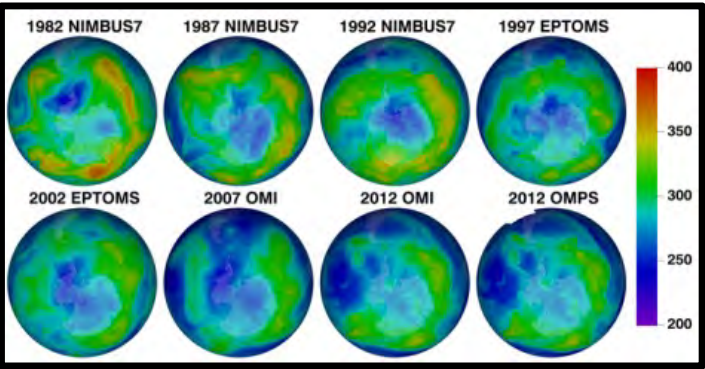

OMPS (Image: NASA) 


\section{Organizational Costs of Jointness}

- Misalignment of Mission

Responsibility \& Decision Authority

- Optimized convergence strategy separated TSPR-like prime contractor from the components \& interfaces for which it was ultimately responsible

- Separate NPOESS \& NPP program offices fractionated decision authority \& crippled decision-making from instrument vendors through agency leadership

- Misalignment of Mission \& Financial Responsibility

- NPP program office's ability to make cost-risk trades was impeded by its lack of financial responsibility for the program's instruments

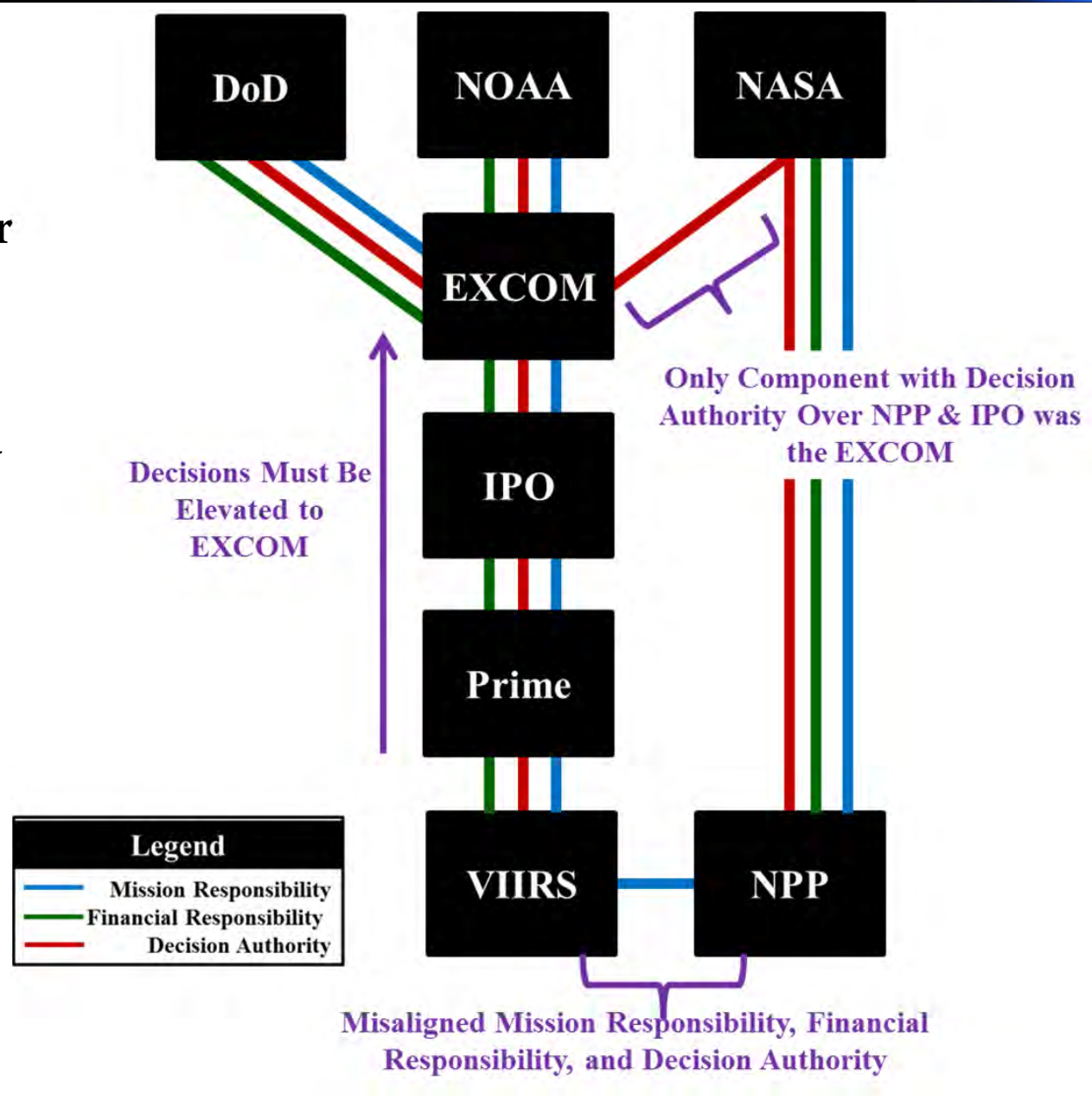

Most of the program's organizational complexity \& non-technical cost growth was a result of the disaggregation, rather than the aggregation, of critical relationships between organizational components. 


\section{A Future for Jointness?}

- Technical Strategies to Mitigate Cost

\section{Growth}

- Recognize that joint requirements hinder a program's ability to leverage individual agencies' heritage capabilities and budget for technology development

- Utilize common standards or invest in nonrecurring system engineering effort to reconcile different standards

- Budget for interactions between instruments and for the cost of spacecraft aggregation

- Organizational Strategies to Mitigate

\section{Cost Growth}

- Award contracts early in the system's lifecycle and concurrently for all of the system's components

- Fully integrate responsibility, authority, and

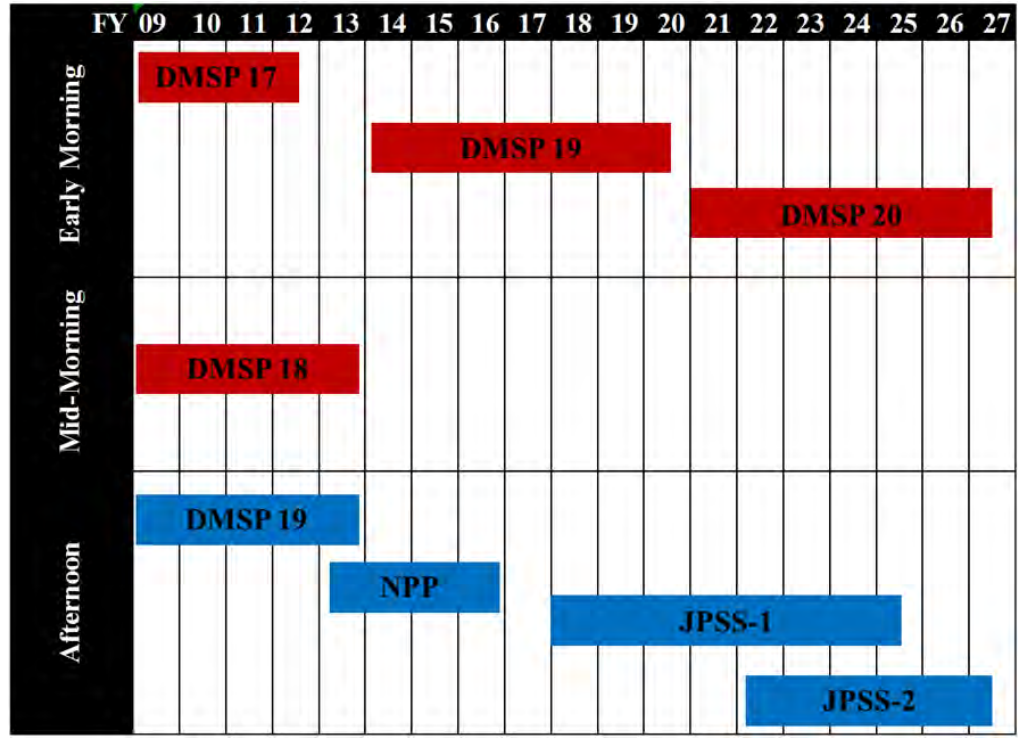
technical capability into a single program office

- Institute a PEO-like authority structure over the user community to enable capability reductions

Planned fly-out of existing environmental satellites in low-earth orbit: An opportunity for another joint program? (Image: NOAA 2013) 


\section{Key Recommendation}

Both aggregated and disaggregated programs can be developed cost effectively as long as their organizational

\section{\& technical architectures match.}

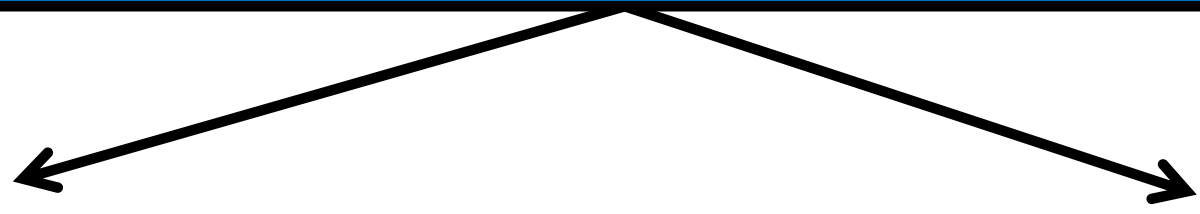

Aggregated System

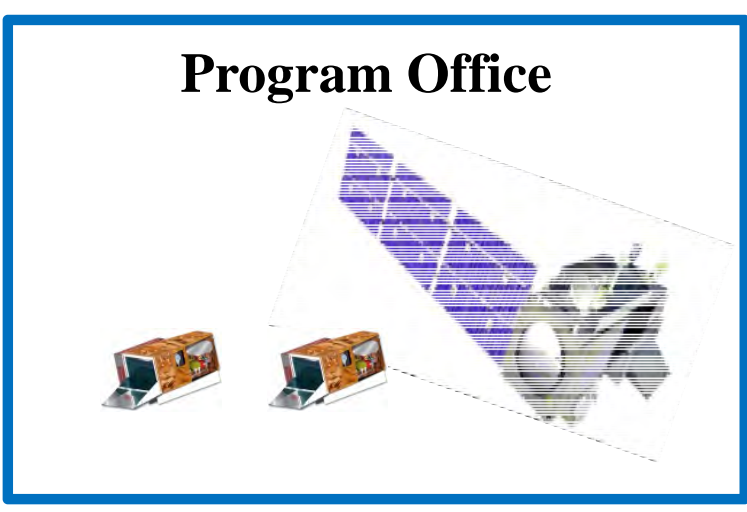

Aggregated systems should be developed by fully aggregated organizations with single program offices.
Disaggregated System

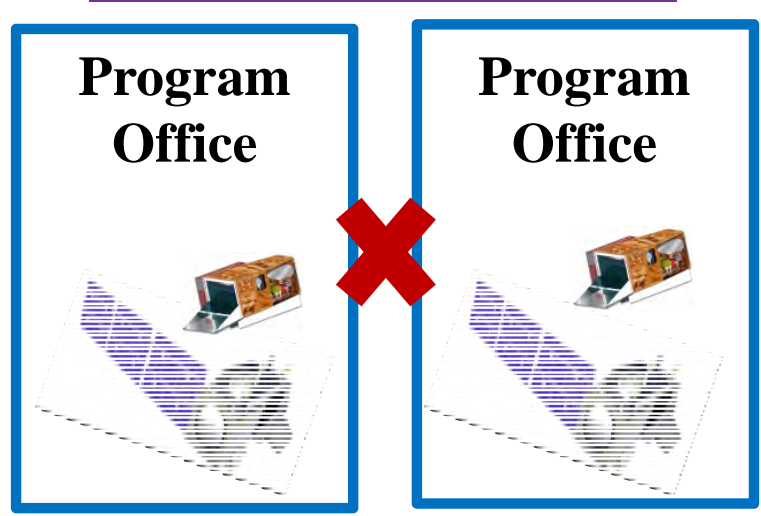

Disaggregated systems should also be developed by single program offices and these offices should be disaggregated from one another. 


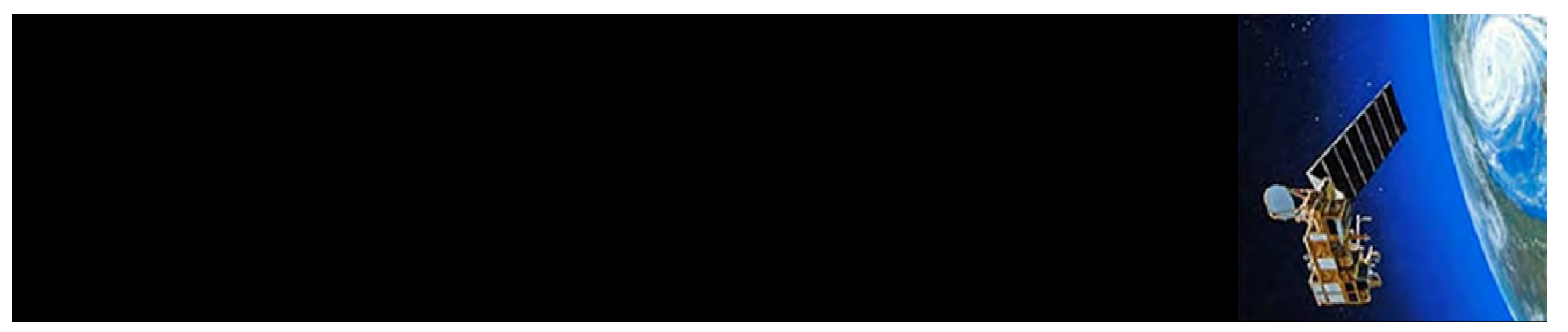

\section{Thanks!}

Please email mdwyer@mit.edu with questions. 
- $\quad$ Alibay, F.; Strange, N. “Trade Space Evaluation of Multi-Mission Architectures for the Exploration of Europa.” Proceedings of the 2013 IEEE Aerospace Conference. Big Sky, Montana, 2013.

- $\quad$ Burch, R. "OPS: Disaggregation \& Diversification of U.S. MILSATCOM." Milsat Magazine. 2012 April 2012.

- Committee on the Assessment of Impediments to Interagency Cooperation on Space and Earth Science Missions. Assessment of Impediments to Interagency Collaboration on Space and Earth Science Missions. Washington, D.C.: The National Academies Press; 2011.

- Committee on Earth Studies, Space Studies Board, National Research Council. Issues in the Integration of Research and Operational Satellite Systems for Climate Research: Part 1: Science and Design. Washington, D.C.: The National Academies Press; 2000.

- Hall, T. NPOESS Lessons Evaluation: Executive Summary. El Segundo, CA: The Aerospace Corporation Space Systems Division, 2010. Report No.: ATR-2011(5558)-1.

- Isbell, D.; Viets, P.; Simms, D. “Agencies Establish New Civil-Military Satellite Program.” NASA Headquarters Press Release 9582. June 1995. Available online: http://www.nasa.gov/home/hqnews/1995/95-82.txt. Accessed 12/8/2013.

- Lubchenco, J. Statement to the House Committee on Science, Space, and Technology. An Overview of the National Oceanic and Atmospheric Administration and the Environmental Protection Agency Budgets for the Fsical Year 2013, Hearing March 6, 2012 (Serial 112-67). Available at: http://www.gpo.gov/fdsys/pkg/CHRG-112hhrg73125/html/CHRG -112hhrg73125.htm. Accessed 12/8/2013.

- Powner, D. Statement to the House Committee on Science. Ongoing Problems and Future Plans for NOAA's Weather Satellites, Hearing November 16, 2005 (Serial 109-33). Available at http://www.gpo.gov/fdsys/pkg/CHRG109hhrg24525/pdf/CHRG-109hhrg24525.pdf. Accessed 12/8/2013.

- Sinha, K.; de Weck. O. "Structural Complexity Quantification for Engineered Complex Systems and Implications on System Architecture and Design." Proceedings of the International Design Engineering Technical Conference. Portland, Oregon, 2013.

- Teets, P. Statement to House Subcommittee on Environment, Technology and Standards. NOAA Satellites: Will Weather Forecasting Be Put At Risk?, Hearing July 15, 2003 (Serial 108-19). Available at: http://www.gpo.gov/fdsys/pkg/CHRG-108hhrg88230/html/CHRG-108hhrg88230.htm. Accessed 12/8/2013.

- Young, T. Statement to the House Subcommittee on Investigations and Oversight of the Committee on Science and Technology. Continuing Independent Assessment of The National Polar-Orbiting Operational Environmental Satellite System, Hearing June 17, 2009 (Serial 111-36). Available at: http://gop.science.house.gov/Media/hearings/oversight09/june17/young.pdf. Accessed 12/8/2013. 


\section{Image Citations}

\section{- $\quad$ Title Slide \& Slide Headers}

- $\quad$ Slide 1

Image of NPOESS Satellite: Wikapedia. Available online: http://en.wikipedia.org/wiki/File:NPOESS illustration 2006.jpg. Accessed 12/8/2013

- $\quad$ Image of Satellite Constellation: Cunningham, J. (System Program Director, Integrated Program Office)“NPOESS: National Polar-orbiting Operational Environmental Satellite System” Satellite Direct Readout Conference for the Americas. 11 December 2002.

- Image of VIIRS Instrument: “Instrument Suite on NPOESS: Direct Readout User’s Conference.” December 9-13, 2002. Available online: noaasis.noaa.gov/NOAASIS/pubs/MIAMI/bloom_p.ppt. Accessed 12/8/2013.

- Image of Ground System: Goldberg, A. “NPOESS Program Overview.” HDF Workshop IX, December 2005.

- Image of Satellite: EO: Sharing Earth Observation Resources: Available online: http://www.eoportal.org/directory/pres_NPPNPOESSPreparatoryProject.html. Accessed 12/8/2013

- $\quad$ Image of Launch Vehicle: Wikapedia. Available online: http://cs.wikipedia.org/wiki/Delta_IV.. Accessed 12/8/2013.

- $\quad$ Slide 3

- $\quad$ AEHF: Spaceflight Now. Available online: http://www.spaceflightnow.com/atlas/av019/status.html. Accessed 12/8/2013.

- $\quad$ EOS: NASA. Available online: http://aetd.gsfc.nasa.gov/code580/code585.html. Accessed 12/8/2013/

- $\quad$ GPS: Universite Catholique de Louvain. Available online: http://www.elic.ucl.ac.be/repomodx/elic/index.php?id=199. Accessed 12/8/2013.

- $\quad$ SIBRS: Los Angeles Air Force Base. Available online: http://www.losangeles.af.mil/library/factsheets/factsheet.asp?id=5514. Accessed 12/8/2013.

- $\quad$ DMSP: FAS: Space Policy Project. Available online: http://www.fas.org/spp/military/program/met/dmsp-5d.htm. Accessed 12/8/2013.

- DSP: FAS: Space Policy Project. Available online: http://www.fas.org/spp/military/program/warning/dsp.htm. Accessed 12/8/2013.

- $\quad$ Fermi: Stanford. Available online: http://fgst.slac.stanford.edu/. Accessed 12/8/2013.

- $\quad$ ACE: University of Michigan. Available online: http://solar-heliospheric.engin.umich.edu/missions.php. Accessed 12/8/2013.

- JPSS: NASA. Available online: http://npp.gsfc.nasa.gov/jpss.html. Accessed 12/8/2013/

- $\quad$ LDCM: NASA: Available online: http://www.nasa.gov/mission pages/landsat/main/LDCM next prt.htm. Accessed 12/8/2013.

- $\quad$ GOES: NASA. Available online: http://www.goes-r.gov/. Accessed 12/8/2013.

- NPOESS: Defense Industry Daily. Available online: http://www.defenseindustrydaily.com/major-shifts-flow-from-npoess-polar-satellite-program-crisis-01557/ Accessed 12/8/2013

- $\quad$ Slide 10

- Image of Satellite: EO: Sharing Earth Observation Resources: Available online: http://www.eoportal.org/directory/pres_NPPNPOESSPreparatoryProject.html. Accessed 12/8/2013 